Diogo Kramel

Desenvolvimento de uma ferramenta para otimização paramétrica da resistência hidrodinâmica de veleiros através da série de Delft

São Paulo 

Diogo Kramel

\title{
Desenvolvimento de uma ferramenta para otimização paramétrica da resistência hidrodinâmica de veleiros através da série de Delft
}

\author{
Versão corrigida
}
Dissertação apresentada à Escola Politécnica da Universidade de São Paulo para obtenção do título de Mestre em Ciências.

Orientador: Prof. Dr. Alexandre Nicolaos Simos

São Paulo 
Autorizo a reprodução e divulgação total ou parcial deste trabalho, por qualquer meio convencional ou eletrônico, para fins de estudo e pesquisa, desde que citada a fonte.

Este exemplar foi revisado e corrigido em relação à versão original, sob responsabilidade única do autor e com a anuência de seu orientador.

São Paulo, 18 de maio 2021

Assinatura do autor:

Assinatura do orientador:

\section{Catalogação-na-publicação}

\section{Kramel, Diogo}

Desenvolvimento de uma ferramenta para otimização paramétrica da resistência hidrodinâmica de veleiros através da série de Delft / D. Kramel -versão corr. -- São Paulo, 2021.

$78 \mathrm{p}$.

Dissertação (Mestrado) - Escola Politécnica da Universidade de São Paulo. Departamento de Engenharia Naval e Oceânica.

1.VELA 2.ALGORITMOS GENÉTICOS 3.RESISTÊNCIA AO AVANÇO I.Universidade de São Paulo. Escola Politécnica. Departamento de Engenharia Naval e Oceânica II.t. 
Nome: KRAMEL, Diogo

Título: Desenvolvimento de uma ferramenta para otimização paramétrica da resistência hidrodinâmica de veleiros através da série de Delft

Dissertação apresentada à Escola Politécnica da Universidade de São Paulo para obtenção do título de Mestre em Ciências.

Aprovado em:

Banca examinadora

Prof. Dr.

Instituição:

Julgamento:

Prof. Dr.

Instituição:

Julgamento:

Prof. Dr.

Instituição:

Julgamento: 



\section{Agradecimentos}

Ao meu professor e orientador, Alexandre Simos, pelas horas que dispôs à sanar minhas dúvidas e pela paciência quando deixei de cumprir com prazos.

O presente trabalho foi realizado com apoio da Coordenação de Aperfeiçoamento de Pessoal de Nível Superior - Brasil (CAPES) - Código de Financiamento 001. 



\section{Resumo}

A avaliação do desempenho de veleiros tem sido realizada por projetistas e arquitetos navais desde o início da navegação através da experiência adquirida e experimentação. A base científica cresceu partindo da identificação dos fatores-chave que mais influenciam o desempenho, como comprimento, boca, deslocamento, para uma compreensão muito mais robusta da complexidade inerente às forças e momentos envolvidos no sistema de equilíbrio que compõe um veleiro.

Recentemente, o aumento no poder computacional tornou possível realizar essa avaliação de forma sistemática. Isso inclui o cálculo detalhado de forças para prever o comportamento de um veleiro e, finalmente, seu desempenho sob diferentes condições de operação.

Portanto, o objetivo deste estudo foi estabelecer uma metodologia para analisar o desempenho de veleiros em águas calmas e ondas usando a série sistemática de Delft para estimar as forças hidrodinâmicas envolvidas. As forças calculadas são integradas a algoritmos genéticos buscando investigar alternativas para as dimensões do casco a fim de minimizar as forças hidrodinâmicas totais.

Por último, essa metodologia é incorporada à uma ferramenta disponibilizada online destinada a avaliar o desempenho de veleiros à vela em uma ampla gama de condições do mar.

Palavras-chaves: Veleiro. Otimização. Resistência hidrodinâmica. 



\section{Abstract}

The evaluation of the performance of sailing yachts has been carried out by naval architects since the very beginning of sailing through experience and experimenting. The scientific basis has grown from identifying key factors that influence performance the most, such as length, beam, displacement, to a much more complete understanding of the inherent complexity in forces and coupling moments involved in the equilibrium system of sailing yachts.

In recent years, the advent of computers has made it possible to perform this assessment in a systematic manner. This includes the detailed calculation of forces to predict the behavior of a sailing yacht and ultimately its performance under different conditions of operation.

Therefore, the aim of this study was to establish a methodology to analyze the performance of sailing yachts in calm waters and waves using the Delft Systematic Yacht Hull Series to estimate the hydrodynamic forces involved. The forces calculate are coupled with a genetic algorithm to investigate alternative solutions of hull dimensions in order to minimize total hydrodynamic forces.

Ultimately, this methodology is incorporated into an online tool capable of assessing the performance of sailing yachts in a wide range of sea states.

Key-words: Sailing yacht. Optimization. Hydrodynamic resistance. 



\section{Lista de ilustrações}

Figura 1 - Mudança no casco dos vencedores da America's Cup ao longo das décadas 21

Figura 2 - Componentes da resistência total assumidas neste trabalho . . . . . . . 30

Figura 3 - Comparativo para comprimento de onda . . . . . . . . . . . . 34

Figura 4 - Comparativo para ângulo de onda . . . . . . . . . . . . 35

Figura 5 - Comparativo com para ângulo de incidência de 140 graus . . . . . . . . 36

Figura 6 - Componentes da resistência para o casco Sysser 1 . . . . . . . . . . 37

Figura 7 - Componentes da resistência para o casco Sysser 60 . . . . . . . . . 37

Figura 8 - Funcionamento do AG aplicado . . . . . . . . . . . . . 38

Figura 9 - Comparativo entre diferentes algoritmos genéticos . . . . . . . . . . 39

Figura 10 - Página introdutória . . . . . . . . . . . . . . . . . 50

Figura 11 - Análise preliminar . . . . . . . . . . . . . . . 50

Figura 12 - Definição do problema e configuração da otimização . . . . . . . . . . . 51

Figura 13 - Resultado preliminar . . . . . . . . . . . . . . . . . 52

Figura 14 - Análise de desempenho . . . . . . . . . . . . . . . . . 54

Figura 15 - Casco-mãe série I (Sysser 1) . . . . . . . . . . . . . . . 56

Figura 16 - Casco-mãe série II, III e VII (Sysser 25) . . . . . . . . . . . . . . 56

Figura 17 - Otimização para diferentes faixas de Froude e adernamento . . . . . . . 57

Figura 18 - Variação das dimensões ao final do processo . . . . . . . . . . . . . 58

Figura 19 - Otimização para diferentes faixas de Froude . . . . . . . . . . . . . . . 59

Figura 20 - Variação das dimensões ao final do processo . . . . . . . . . . . . . . . 60

Figura 21 - Otimização para resistência em águas calmas e adicional em ondas . 61

Figura 22 - Dimensões variando no processo . . . . . . . . . . . . . . . . . . 62

Figura 23 - Sensibilidade média para resistência em águas calmas . . . . . . . . . . 65

Figura 24 - Relação entre parâmetros e resistência residual . . . . . . . . . . . . . . 66

Figura 25 - Casco-mãe Série I (Sysser 1) . . . . . . . . . . . . . . . . 75

Figura 26 - Casco-mãe Séries II, III, VII (Sysser 25) . . . . . . . . . . . . . . . 75

Figura 27 - Casco-mãe Série IV (Sysser 44) . . . . . . . . . . . . . . . . . 75

Figura 28 - Casco-mãe Série VI (Sysser 60) . . . . . . . . . . . . . . . 76

Figura $29-\mathrm{YD}-40 \ldots \ldots \ldots \ldots \ldots \ldots$ 



\section{Lista de tabelas}

Tabela 1 - Dimensões dos veleiros utilizados no processo . . . . . . . . . . . . . 42

Tabela 2 - Restrições adimensionais da série sistemática . . . . . . . . . . . 44

Tabela 3 - Restrições de segurança e conforto . . . . . . . . . . . . . . 47

Tabela 4 - Parâmetros principais do algoritmo . . . . . . . . . . . 47

Tabela 5 - Dimensões principais dos veleiros utilizados no estudo de caso . . . . . 55

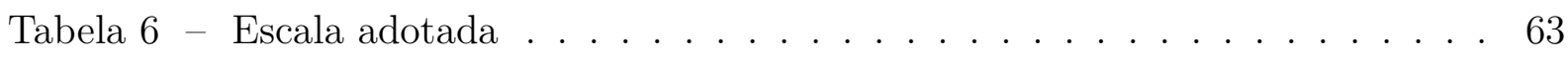





\section{Lista de abreviaturas e siglas}

$\begin{array}{ll}\text { CMAES } & \text { Covariance Matrix Adaptation Evolution Strategy } \\ \text { CEE } & \text { Capsize Screening Factor } \\ \text { CFD } & \text { Curva de Estabilidade Estática } \\ \text { DoE } & \text { Computational Fluid Dynamics } \\ \text { DSYHS } & \text { Delft Systematic Yacht Hull Series } \\ \text { EpsMOEA } & \text { Epsilon Multiobjective Evolutionary Algorithm } \\ \text { GDE3 } & \text { Generalized Differential Evolution } \\ \text { IBEA } & \text { Indicator-based Evolutionary Algorithm } \\ \text { ITTC } & \text { International Towing Tank Conference } \\ \text { MCR } & \text { Motion Comfort Ratio } \\ \text { MOEAD } & \text { Multiobjective Evolutionary Algorithm Based on Decomposition } \\ \text { NSGA } & \text { Non-Dominated Sorting Genetic Algorithm } \\ \text { OMOPSO } & \text { Multi-Objective Particle Swarm Optimizer } \\ \text { SPEA2 } & \text { Strength Pareto Evolutionary Algorithm } \\ \text { VMP } & \text { Velocity Made Good } \\ \text { Velocity Prediction Program }\end{array}$





\section{Lista de símbolos}

\begin{tabular}{|c|c|}
\hline$\nabla_{c}$ & Deslocamento volumétrico do casco \\
\hline$\Delta_{c}$ & Deslocamento em massa do casco \\
\hline$\rho$ & Densidade da água \\
\hline$\lambda$ & Comprimento de onda \\
\hline$\omega_{e}$ & Frequência de encontro da onda \\
\hline$\zeta_{a}$ & Amplitude de onda \\
\hline$\theta$ & Ângulo de incidência de onda \\
\hline$\phi$ & Ângulo de adernamento \\
\hline$A_{W P}$ & Área do plano d'água \\
\hline$B_{O A}$ & Boca máxima \\
\hline$B_{W L}$ & Boca à linha d'água \\
\hline$B R$ & Razão de lastro \\
\hline$C_{B}$ & Coeficiente de bloco \\
\hline$C_{F}$ & Coeficiente friccional \\
\hline$C_{M}$ & Coeficiente de área da seção mestra \\
\hline$C_{P}$ & Coeficiente prismático \\
\hline$C_{W P}$ & Coeficiente de linha d'água \\
\hline$F_{n}$ & Número de Froude \\
\hline$g$ & Aceleração da gravidade \\
\hline$H_{S}$ & Altura significativa de onda \\
\hline$K_{Y Y}$ & Raio de giração \\
\hline
\end{tabular}




$\begin{array}{ll}L_{O A} & \text { Comprimento total } \\ L_{W L} & \text { Comprimento linha d'água } \\ L C B & \text { Centro longitudinal de carena } \\ L C F & \text { Centro longitudinal de flutuação } \\ R_{A W} & \text { Resistência adicional em onda } \\ R_{F} & \text { Resistência friccional } \\ R_{R} & \text { Resistência residual } \\ R_{T} & \text { Resistência total } \\ R e & \text { Número de Reynolds total } \\ S_{C B} & \text { Área da superfície molhada } \\ S_{\zeta} & \text { Densidade espectral } \\ T_{C} & \text { Calado moldado } \\ T_{P} & \text { Período de pico } \\ V & \text { Velocidade }\end{array}$




\section{Sumário}

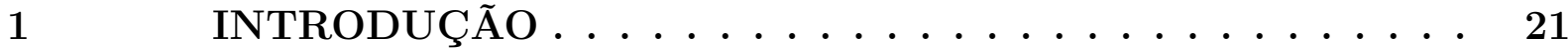

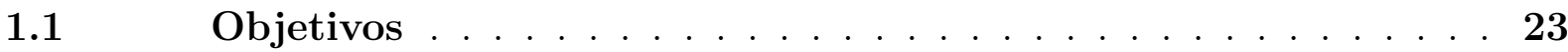

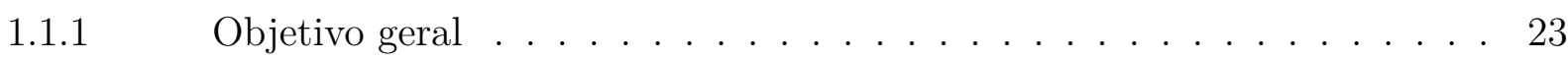

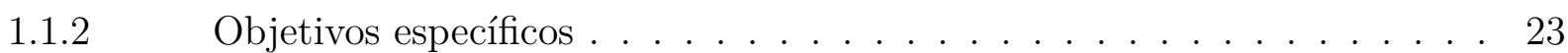

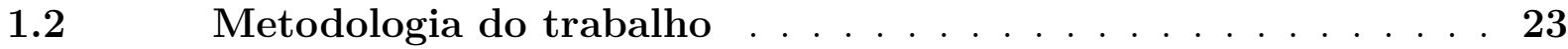

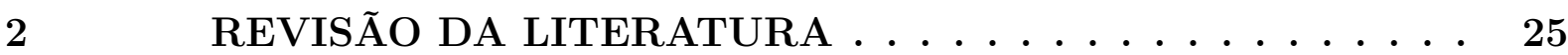

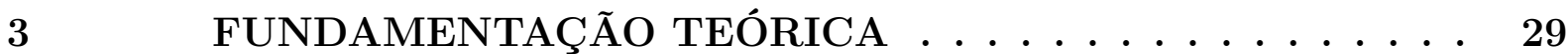

3.1 Análise hidrodinâmica do casco . . . . . . . . . . . . 29

3.1 .1 Resistência friccional . . . . . . . . . . . . . . . 30

3.1.2 Resistência residual . . . . . . . . . . . . . . . . . . . 31

3.1.3 Resistência devido a inclinação do casco . . . . . . . . . . . . . . . . 31

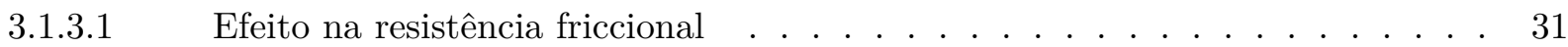

3.1.3.2 Efeito na resistência residual $\ldots \ldots \ldots \ldots \ldots$

3.1.4 Resistência adicional em ondas . . . . . . . . . . . . . . . . . . . 32

3.1.5 Resistência total . . . . . . . . . . . . . . . . . . 36

3.2 Técnicas de otimização $\ldots \ldots \ldots \ldots \ldots$

4 METODOLOGIA DO PROCESSO DE OTIMIZAÇÃO . . . 41

4.1 Variáveis do processo de otimização . . . . . . . . . . . 41

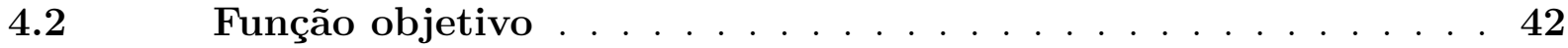

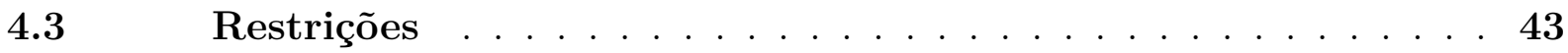

4.3.1 Restrições do modelo . . . . . . . . . . . . . . . . . . . . 43

4.3.2 Restrições de segurança . . . . . . . . . . . . . . . . . . . . . . 44

4.3 .3 Restrições de conforto . . . . . . . . . . . . . . . . . . . 46

$4.4 \quad$ Algoritmo de otimização $\ldots \ldots \ldots \ldots \ldots$

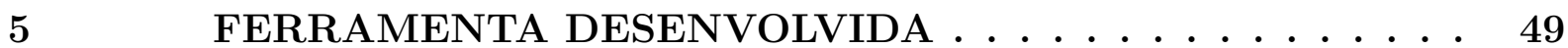

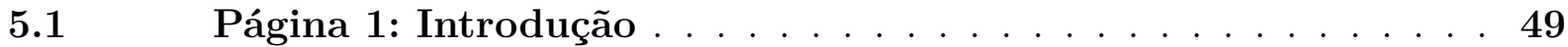

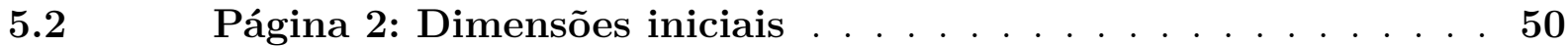

5.3 Página 3: Definir o escopo da otimização . . . . . . . . . 51 
$5.4 \quad$ Página 4: Resultados preliminares . . . . . . . . . . . 52

$5.5 \quad$ Página 5: Avaliação com apêndices e velames . . . . . . . . 53

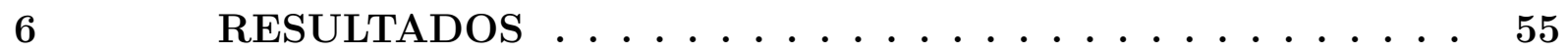

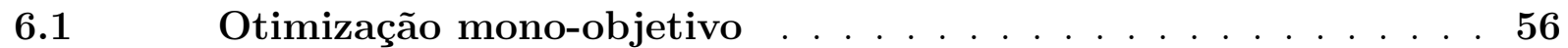

6.1.1 Resistência em águas calmas . . . . . . . . . . . . . . . . . 57

6.1.2 Resistência total . . . . . . . . . . . . . . . . 59

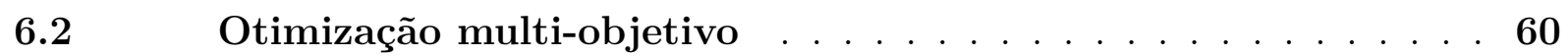

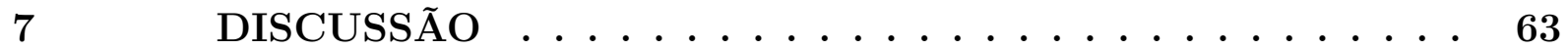

7.1 Seleção do melhor indivíduo . . . . . . . . . . . . 63

$7.2 \quad$ Sensibilidade aos parâmetros . . . . . . . . . . . . . . 64

7.3 Análise do coeficiente prismático e LCB . . . . . . . . . . . . . 65

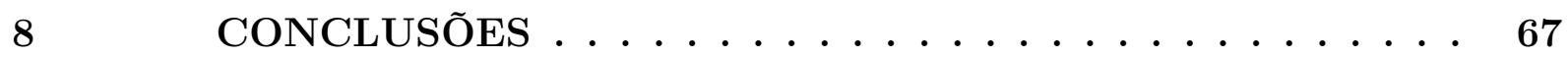

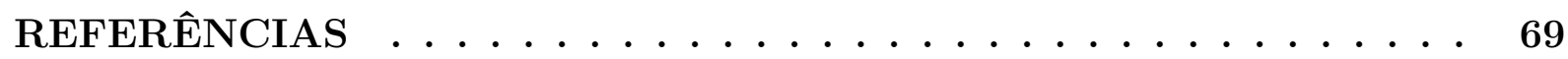

$\begin{array}{ll}\text { APÊNDICES } & 73\end{array}$ 


\section{Capítulo 1}

\section{Introdução}

Por mais de 5 mil anos, seja através de métodos empíricos ou científicos, constantes avanços tecnológicos na concepção de veleiros ocorreram em busca de melhor desempenho, conforto e segurança. Mais recentemente, estes avanços foram impulsionados significativamente pelas mais recentes práticas recreativas e desportivas, especialmente por regatas de prestígio como a America's Cup e a Volvo Ocean Race, que motivaram mudanças drásticas no projeto de veleiros (1). Competições como essas e a demanda cada vez mais exigente dos usuários permitiram que grandes investimentos em pesquisa fossem feitos ao longo dos últimos anos, resultando na melhoria de aspectos como peso, hidrodinâmica e materiais empregados (SPALATELU-LAZAR; LÉNÉ; TURBÉ, 2008) e consolidação do uso de ferramentas ao longo do projeto, e.g. CFD.

Figura 1 - Mudança no casco dos vencedores da America's Cup ao longo das décadas

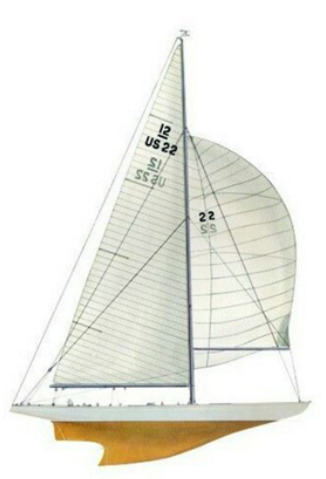

Intrepid - 1970

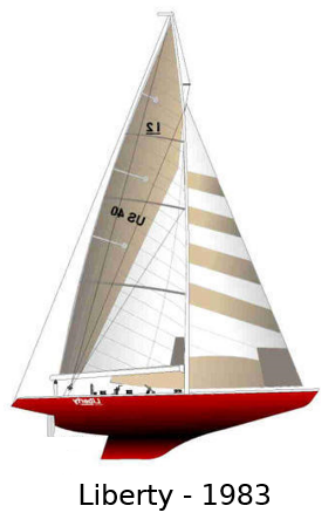

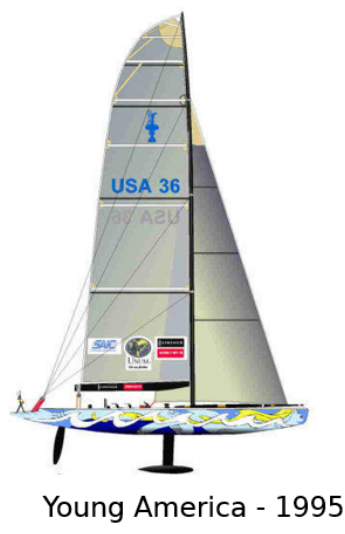

À medida que a tecnologia avançou e o entendimento da física envolvida tornou-se mais claro, vários parâmetros que caracterizam a geometria, as forças e momentos atuantes em um veleiro foram derivados com o propósito de correlacionar de forma quantitativa o desempenho com estes parâmetros (FASSARDI; HOCHKIRCH, 2006).

Contudo, no projeto típico de veleiros, os projetistas enfrentam várias restrições de projeto, necessitando balancear relações de compromisso conflituosas ou, no caso de 
competições, desenvolver um projeto que atenda um certo handicap. O desenvolvimento deste tipo de projeto comumente gera desafios de grande complexidade, não apenas devido aos efeitos fluido-dinâmicos envolvidos, mas também as complexas interações entre forma e peso que determinam o comportamento dinâmico do veleiro e seu desempenho (FOSSATI, 2009).

Apesar dos avanços na modelagem do desempenho de veleiros, a exploração sistemática de outras possibilidades com o objetivo de encontrar melhores alternativas de design para um determinado conjunto de requisitos continua sendo um esforço custoso e nem sempre intuitivo. O projetista se depara com questões como: Qual seria o comprimento ideal? Como variações na boca do casco afetariam a estabilidade da embarcação? Um casco mais delgado seria melhor do que um mais bojudo?

Larsson e Eliasson (2001) vai além e define o problema com um processo de natureza essencialmente quantitativa e, ainda que a resposta para as perguntas acima seja crucial, o projetista deve sobretudo estimar valores que qualifiquem de forma numérica estas questões.

A exploração de soluções e alternativas neste contexto é realizada por tentativa e erro (LARSSON; ELIASSON, 2001), e mesmo que essa possa ser sistematizada, é comum que certas alternativas de design não sejam exploradas devido ao tempo limitado do projeto, recursos econômicos e técnicos (FASSARDI; HOCHKIRCH, 2006).

A maior dificuldade neste processo reside não apenas em responder tais questões individualmente mas também avaliar uma série de contrapartidas e efeitos cumulativos, panorama similar a maioria dos problemas de engenharia.

No caso de um iate a motor ou navio, o objetivo mais comum é minimizar a resistência ao avanço e a potência instalada requerida dentro das restrições das dimensões exigidas, deslocamento e custo. Para um veleiro, este problema é mais complexo (DEBORD et al., 2002). As velas impelem a embarcação através do empuxo aerodinâmico gerado, que em contrapartida é limitado pelo tamanho e eficiência das velas, assim como pela capacidade do veleiro em converter a força total da vela em impulso avante. Em situações de velejo a contravento (orça), esta última característica é afetada pela restauração hidrostática do casco necessária para contrabalançar os efeitos da força lateral das velas, no qual apêndices como a quilha desempenham papel crucial.

Ao considerar o desempenho durante condições diversas de mar, esses trade-offs se tornam ainda mais complexos pelo fato de que o desempenho em condições mais e menos favoráveis de vento são importantes, sob os quais certos parâmetros de design são benéficos em um modo e prejudiciais em outro (FOSSATI, 2009).

Em virtude da multiplicidade de fatores envolvidos no projeto de veleiros, diversos trabalhos se dedicaram à melhoria e/ou otimização das dimensões de veleiros a fim de 
assegurar melhorias no desempenho da embarcação. Desempenho, neste contexto, pode se referir a velocidade, conforto, uso de materiais, processo de manufatura, entre outros. Este trabalho se dedica ao primeiro caso, explorando alternativas que sistematizem este projeto e auxilie o processo de variações de múltiplos parâmetros ao longo das etapas iniciais de projeto.

\subsection{Objetivos}

\subsubsection{Objetivo geral}

Desenvolver uma plataforma para uso acadêmico destinada à melhoria do desempenho de cascos de veleiros em termos de velocidade através do cálculo da resistência em águas calmas e da resistência adicional em ondas pela série sistemática de Delft com auxílio de métodos de otimização.

\subsubsection{Objetivos específicos}

- Implementar a série sistemática de Delft no cálculo da resistência total e resistência adicional em ondas como funções objetivo no processo de otimização;

- Entender como as dimensões do casco nu, quando alteradas, afetam o desempenho final da embarcação e quais as relações de compromisso envolvidas;

- Desenvolver uma plataforma online aplicando a metodologia desenvolvida, disponibilizando um repositório com versão de controle para desenvolvimento livre.

Evidentemente, a análise exclusiva do casco nu pode mascarar soluções que, quando consideradas a resistência aerodinâmica e a inclusão de apêndices, sejam menos eficientes que seus pares.

\subsection{Metodologia do trabalho}

A metodologia proposta neste trabalho é composta de duas partes. A primeira delas busca apresentar a formulação da série de Delft empregada no trabalho para determinar a resistência hidrodinâmica total do casco. Na segunda parte, algoritmos genéticos são incorporados aos cálculos de resistência em um processo de otimização através de algoritmos genéticos.

O desenvolvimento deste modelo de otimização inclui a criação restrições aplicáveis ao modelo como forma de avaliar a viabilidade das soluções encontradas. Estas restrições incluem fatores de forma, restrições do modelo empregado e fatores de segurança e conforto. 
Ao final, para avaliar os resultados obtidos, um um estudo de caso é conduzido com cascos representativos de veleiros de regata e cruzeiros em diferentes condições de mar e de operação.

Ao longo do trabalho, referências a ferramenta desenvolvida serão feitas visando contextualiza-la pela perspectiva do usuário. 


\section{Capítulo 2}

\section{Revisão da literatura}

A série sistemática de Delft começou a ser desenvolvida em 1974 pelo Laboratório de Hidromecânica da Universidade de Delft e tem sido aprimorada desde então. Séries sistemáticas consistem em experimentos com modelos em escala reduzida em tanques de prova. Até o momento, a série contém 73 cascos derivados de cinco cascos-mãe (KEUNING; KATGERT, 2008) que acompanham as mudanças de forma e desempenho de veleiros ao longo dos anos. Graças a variedade de veleiros adicionados à série, acredita-se que ela é capaz de gerar resultados confiáveis para uma vasta gama de veleiros dentro das limitações inerentes ao ensaio em escala reduzida(KEUNING; SONNENBERG, 1998).

Ademais, para capturar as mudanças no projeto de veleiros mais recentes que se encaminham para cascos mais delgados e rápidos, o trabalho de Kleijweg (2016) propôs a adição de mais 20 cascos para avaliar os efeitos hidrodinâmicos em intervalos de número de Froude até 0.95 , aumentando a abrangência da série que anteriormente se limitava a valores máximos 0.6 (KEUNING; KATGERT, 2008). Complementarmente, os cascos iniciais que compõe as Séries I, II, III e IV foram testados novamente para números de Froude de até 0.75 , alterando no processo os coeficientes utilizados nas regressões polinomiais e sua formulação (FOSSATI, 2009).

Outro avanço na série foi a inclusão mais recentemente do efeito da resistência adicional em ondas, proposto por Keuning, Vermeulen e Have (2006), que pode ter um efeito significativo na modelagem da resistência total do veleiro, a depender das condições de mar sob análise. O resultado é um avanço em relação ao método inicial apresentado pelo mesmo autor oito anos antes em Keuning e Sonnenberg (1998). Neste caso, diferentemente do restante da série, a resistência adicional em ondas foi calculada computacionalmente utilizando um modelo de teoria das faixas, ao invés de modelos em escala e tanques de prova.

Diferentemente das outras componentes da resistência hidrodinâmica, a resistência adicional em ondas incorpora parâmetros menos usuais, como o momento de inércia da área de linha d'água em pitch da embarcação. O trabalho de Ottosson, Brown e Larsson 
(2002) analisou o efeito do raio de giração no desempenho de veleiros, mostrando que há uma influência significativa. Para velocidades de vento de 20 nós e altura de onda de 0.9 metros, o veleiro estudado teve uma variação de VMG de 7.45 para 7.70 nós ao alterar o raio de $5.8 \mathrm{~m}$ para $3.8 \mathrm{~m}$. No entanto, nas velocidades de vento mais baixas e alturas de onda menores a diferença não é tão significativa. Conclusões desse tipo devem ser, de fato, esperadas, já que a resistência adicional em ondas está diretamente associada aos movimentos e à variação de área molhada do casco nas vizinhanças da linha d'água. Assim, as características de resposta em ondas da embarcação, sobretudo as frequências próprias de oscilação em heave e pitch, exercem influência significativa sobre o acréscimo de resistência.

No geral, a modelagem matemática da resistência hidrodinâmica através da série sistemática permitiu que o desempenho de veleiro fosse avaliado de forma mais precisa ao mesmo tempo que permitiu que métodos de otimização paramétrica fossem aplicadas por meio de diversas estratégias.

Uma delas é definir, a priori, um número de Froude desejado para se proceder à otimização e obter os coeficientes da série da Delft utilizados na cálculo da resistência residual. Com base nestes coeficientes, é possível analisar como certas dimensões impactam o valor da resistência. Esta abordagem foi adotada por Larsson e Eliasson (2001) durante o projeto do veleiro YD-40, quando o autor projetou a resistência residual para um intervalo de valores de coeficiente prismático $\left(C_{P}\right)$ e centro de carena (LCB) considerando um número de Froude de 0.35. Segundo o autor, esse valor corresponde à velocidade média esperada em orça em vento moderado, próximo de 15 nós. Através da análise gráfica, o autor então pode apontar qual o valor ideal para cada parâmetro.

Um método mais robusto foi apresentado por Fassardi e Hochkirch (2006) que combina Design of Experiments (DoE) e superfície de resposta. Em seu estudo, 946 cascos hipotéticos foram criados respeitando certos limites dimensionais. Cada uma das soluções é avaliada individualmente em busca do casco com menor resistência. Apesar do uso de força bruta para a resolução do problema, o trabalho mostra que os resultados são satisfatórios tanto para uma malha simples com apenas 30 cascos, quanto também mais detalhada com 946 cascos avaliados.

Contudo, por não propor uma solução sistemática e orientada, este método não é propriamente classificado como otimização. O mesmo não pode ser dito do trabalho de Barbarini (2007), que desenvolveu um algoritmo para geração paramétrica de cascos de veleiros a partir de um conjunto reduzido de dimensões. Este algoritmo, por sua vez, é vinculado a cálculos de resistência através da série de Delft, relacionando as dimensões do casco ao seu desempenho ao longo do processo. Essa abordagem permite que as soluções geradas sejam avaliadas ao longo do processo, reduzindo os custos computacionais e direcionando o algoritmo para mínimos locais. 
Os trabalhos descritos neste capítulo empregam diferentes métodos para sistematizar a buscar por melhores soluções de projeto. Contudo, um método comumente utilizado são os algoritmos genéticos que são ferramentas de busca e otimização inspirados no processo evolutivo. Diversos algoritmos genéticos foram criados desde seu advento. O principal deles é o algoritmo NSGAII (Non-Dominated Sorting Genetic Algorithm II), proposto por Deb et al. (2000) como melhoria do já existente NSGA. Seu funcionamento baseia-se na combinação da população atual com a população anterior, preservando os melhores indivíduos, baseado em uma ordenação de elitismo por dominância.

Ao final, diversos métodos podem ser aplicados na avaliação do desempenho de veleiros com variados graus de robustez. Ainda que diferentes em suas abordagens, eles servem propósitos diferentes e variam, em geral, aumentando a complexidade e precisão ao custo de poder computacional. Em virtude do objetivo do trabalho em desenvolver uma ferramenta acessível para o projeto preliminar de veleiros, os próximos capítulos apresentarão o desenvolvimento de uma metodologia para o uso de algoritmos genéticos na busca de casco com menor resistência hidrodinâmica. 



\section{Capítulo 3}

\section{Fundamentação teórica}

Neste capítulo serão discutidas as bases teóricas e práticas que sustentam os métodos implementados no desenvolvimento deste trabalho. A primeira parte se dedica ao cálculo das componentes da resistência hidrodinâmica do casco através da série sistemática de Delft. A segunda parte apresenta o método de otimização escolhido para a resolução do problema que utiliza como função de mérito a resistência hidrodinâmica através das dimensões principais do casco sem levar em consideração sua superfície. Para tal, apresenta-se o funcionamento de algoritmos genéticos e suas principais propriedades.

\subsection{Análise hidrodinâmica do casco}

O movimento do casco de uma embarcação, dada uma velocidade, através da água leva ao surgimento da força de resistência ao avanço. No caso de veleiros, quando em condição de equilíbrio, a resistência é equivalente à componente longitudinal ao casco da forca motriz gerada pelas velas. Contudo, sobretudo em condições de orça, as velas também geram uma componente transversal que leva a um efeito de deriva e guinada no casco e impõe um momento que provoca seu adernamento (LARSSON; ELIASSON, 2001). Dentro do escopo deste trabalho, a resistência ao avanço do casco nu será utilizada como forma de avaliar o desempenho da embarcação. Tratando-se da análise exclusiva do casco nu, o efeito decorrente dos apêndices, i.e. quilha e leme, não é incluso na análise.

Para Fossati (2009), não há um modelo matemático simples que produza resultados exatos de resistência hidrodinâmica de um veleiro em condições dinâmicas. Contudo, métodos experimentais usando modelos em escala e tanques de prova, como a série sistemática de Delft, são os métodos mais utilizados em projeto, especialmente pela simplicidade e grau de confiança, cujas regressões possuem coeficientes de determinação $\left(R^{2}\right)$ maiores que 0.98 para números de Froude iguais ou maiores que 0.35. Uma das grandes vantagens da série é realizar o cálculo das componentes da resistência hidrodinâmica separadamente, combinando os efeitos apenas ao final da análise. 
O presente trabalho estrutura este cálculo através de três componentes: resistência em calado uniforme, resistência adicional devido a banda e resistência adicional devido ao estado de mar, como ilustrada pela Figura 2. Para o casco em posição estritamente vertical em águas calmas, utiliza-se o modelo de previsão de resistência ao avanço da série DELFT que compreende a separação da resistência proposta por Froude, em uma parcela friccional e uma parcela residual. Estas componente são afetadas quando o veleiro possui um ângulo de banda, cujo efeito é incluído nesta análise. Por último, a resistência adicional em ondas contabiliza os efeitos de ondas sobre o casco. As respetivas formulações são descritas nas seções seguintes.

Figura 2 - Componentes da resistência total assumidas neste trabalho

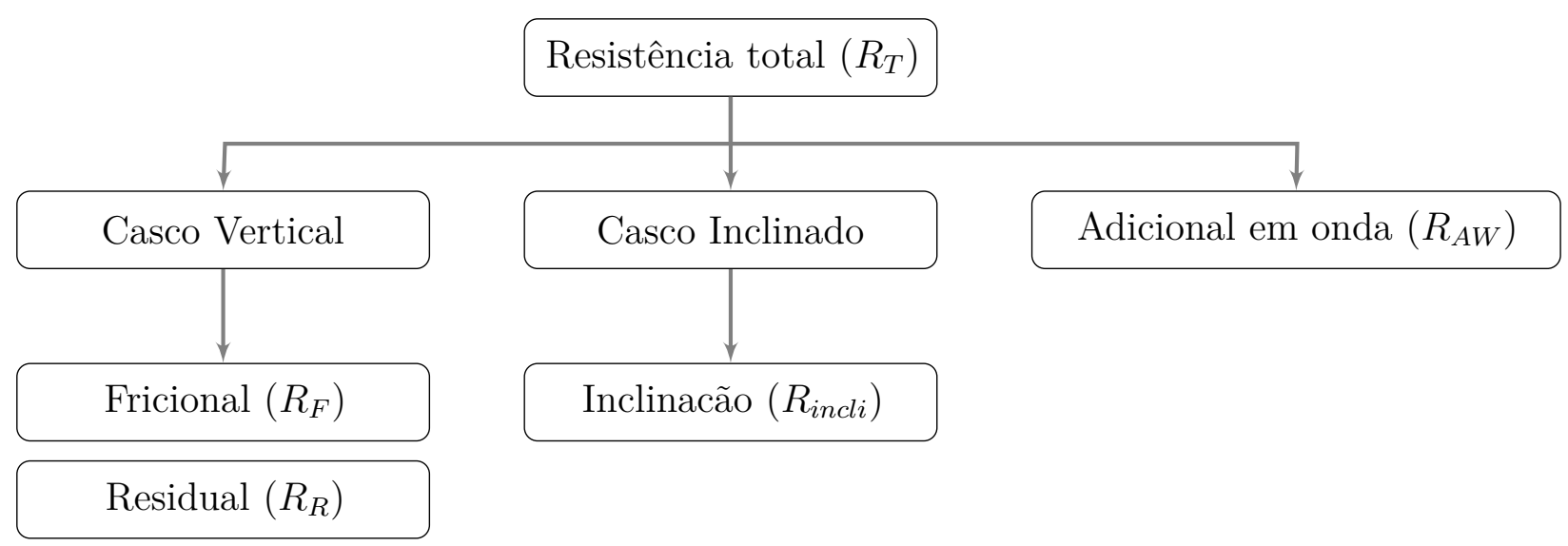

\subsubsection{Resistência friccional}

Para o cálculo da resistência friccional utiliza-se o método desenvolvido originalmente pelo ITTC em 1957 onde a componente de pressão viscosa é extrapolada pelo número de Reynolds e inclui um fator de correção para a estimativa da resistência friccional. Nesta abordagem, o coeficiente friccional é dado pela curva de correlação ITTC-1978 e mostrado na Equação (3.1). Onde Rn corresponde ao número de Reynolds.

$$
C_{F}=\frac{0.075}{(\log (R e)-2)^{2}}
$$

De posse do coeficiente, a resistência friccional pode ser calculada através da Equação (3.2.)

$$
R_{F}=\frac{1}{2} \rho \cdot V^{2} \cdot C_{F} \cdot S_{C B}
$$

Onde $S_{C B}$ é a área da superfície molhada do casco nu, $V$ a velocidade e, $C_{F}$ o coeficiente viscoso. A área da superfície molhada do casco, por sua vez, é aproximada pela formulação de Gerritsma e Keuning (1992), desenvolvida exclusivamente para veleiros. 


$$
S_{C B}=\left(1.97+0.171 \cdot \frac{B_{W L}}{T_{C}}\right) \cdot\left(\frac{0.65}{C_{M}}\right)^{1 / 3} \cdot \sqrt{\nabla_{c} \cdot L_{W L}}
$$

\subsubsection{Resistência residual}

A resistência residual corresponde a uma componente gravitacional que pode ser obtida ao subtrair-se a resistência friccional da resistência total. Este foi o procedimento aplicado na construção da série de Delft. Através de ensaios em tanques de prova, a série propôs um conjunto de coeficientes por meio de uma regressão por mínimos quadrados, totalizando oito coeficientes $\left(a_{i}\right)$ que dependem do número de Froude da embarcação para cada condição. A formulação empregada neste trabalho corresponde à Equação (3.4) proposta por Keuning e Katgert (2008).

$$
\begin{gathered}
\frac{R_{R}}{\nabla_{c} \cdot \rho \cdot g}=a_{0}+\left(a_{1} \cdot \frac{L C B}{L_{W L}}+a_{2} \cdot C_{P}+a_{3} \cdot \frac{\nabla_{c}^{2 / 3}}{A_{W P}}+a_{4} \cdot \frac{B_{W L}}{L_{W L}}\right) \cdot \frac{\nabla_{c}^{2 / 3}}{L_{W L}}+ \\
\left(a_{5} \cdot \frac{L C B}{L C F}+a_{6} \cdot \frac{B_{W L}}{T_{C}}+a_{7} \cdot C_{M}\right) \cdot \frac{\nabla_{c}^{2 / 3}}{L_{W L}}
\end{gathered}
$$

\subsubsection{Resistência devido a inclinação do casco}

As componentes da resistência friccional e residual consideram o casco na vertical sem inclinação. Contudo, é sabido que o veleiro opera majoritariamente em banda, o que incorre em mudanças consideráveis na geometria: a linha d’água se torna assimétrica e as seções transversais mudam de acordo com a inclinação imposta.

As principais consequências destas mudanças, em termos de dimensões, são o aumento ou diminuição do comprimento da linha d'água e a mudança na área molhada (que afeta a resistência friccional). Estas mudanças afetam diretamente as componentes friccional e residual da resistência.

\subsubsection{Efeito na resistência friccional}

A alteração da área molhada implica na mudança da resistência por fricção e seus efeitos são descritos por Keuning e Katgert (2008). O cálculo utiliza a série de Delft para os coeficientes $s_{i}$ e é dada pela Equação (3.5).

$$
\Delta S_{C B}=S_{C B} \cdot\left(1+\frac{1}{100}\left(s_{0}+s_{1} \cdot \frac{B_{W L}}{T_{C}}+s_{2} \cdot\left(\frac{B_{W L}}{T_{C}}\right)^{2}+s_{3} \cdot T_{C}\right)\right)
$$

\subsubsection{Efeito na resistência residual}

O processo para definir as mudanças que ocorrem na resistência residual são descritos por Keuning e Sonnenberg (1998) e são obtidas através de uma estimativa 
baseada no valor calculado para uma inclinação de 20 graus. Este valor de inclinação corresponde ao valor utilizado nos ensaios da série de Delft. A resistência para uma inclinação de 20 graus é dada pela Equação (3.6), que utiliza coeficientes $\left(u_{i}\right)$ proporcionais ao número de Froude e provenientes da série de Delft.

$$
\frac{\Delta R_{R}\left[20^{\circ}\right]}{\nabla_{c} \cdot \rho \cdot g}=u_{0}+u_{1} \cdot \frac{L_{W L}}{B_{W L}}+u_{2} \cdot \frac{B_{W L}}{T_{C}}+u_{3} \cdot\left(\frac{B_{W L}}{T_{C}}\right)^{2}+u_{4} \cdot L C B+u_{5} \cdot L C B^{2}
$$

Para obter os valores correspondentes a outros ângulos de adernamento, utiliza-se a Equação (3.7).

$$
\Delta R_{R}=\Delta R_{R}\left[20^{\circ}\right] \cdot 6.0 \cdot \phi^{1.7}
$$

Ainda que um método mais preciso tenha sido proposto mais recentemente por Keuning e Katgert (2010), sua aplicação torna-se inviável neste presente trabalho por requerer a variação das dimensões de boca, calado, comprimento e coeficiente prismático para cada ângulo de inclinação. Determinar tais variações dimensionais neste estágio exigiria a necessidade de um modelo matemático da superfície do casco.

\subsubsection{Resistência adicional em ondas}

A resistência adicional em ondas representa o acréscimo de resistência verificado quando o barco navega em condição em ondas (seakeeping). O encontro de ondas com a embarcação leva ao movimento de pitch e heave (caturro e afundamento) que são usualmente acoplados entre si.

Quando a frequência de encontro das ondas coincide com o período natural de pitch ou heave, há um aumento significativo na amplitude do movimento, fenômeno conhecido como batimento. A frequência de ondas em alto mar é tipicamente menor que frequência natural do casco, em especial devido ao comprimento relativamente pequeno de veleiros, e portanto as ondas do mar com energia mais significativa têm comprimentos maiores do que estas embarcações. Em águas abrigadas, predominam ondas mais curtas, quando o veleiro fica mais suscetível a maiores acréscimos de resistência (LARSSON; ELIASSON, 2001).

O período natural de pitch da embarcação é determinado em parte pelo momento de inércia da embarcação que, por sua vez, depende da distribuição de massas em relação ao centro de gravidade. Este tipo de estimativa é impraticável em etapas iniciais de projeto e portanto as formulações da série de Delft foram adotadas para estimar a resistência adicional em ondas, propostas através do trabalho de Keuning, Vermeulen e Have (2006). Em testes de validação do modelo, mostrou-se que a o método possui estimativas relativamente precisas para cascos com deslocamento médio, contudo, relações 
comprimento-deslocamento maiores tendem a subestimar o valor de resistência adicional em ondas (FOSSATI, 2009).

Ainda que a equação utilize o mesmo sistema de oito variáveis $\left(a_{i}\right)$ de outras componentes, desta vez, eles são obtidas de forma diferente. Cada valor de $a_{i}$ é obtido através de um conjunto de matrizes que combina números de Froude, ângulo de incidência de onda, raio de giração relativo ao comprimento do casco na linha d'água e relação do comprimento de onda e comprimento na linha d'água. A formulação geral é dada pela Equação (3.8).

$$
\begin{aligned}
R_{A W} & =a_{1} \cdot\left(\frac{L_{W L}}{\nabla_{c}^{1 / 3}}\right)+a_{2} \cdot\left(\frac{L_{W L}}{\nabla_{c}^{1 / 3}}\right)^{2}+a_{3} \cdot\left(\frac{L_{W L}}{\nabla_{c}^{1 / 3}}\right)^{3}+ \\
& a_{4} \cdot\left(\frac{L_{W L}}{B_{W L}}\right)+a_{5} \cdot\left(\frac{L_{W L}}{B_{W L}}\right)^{2}+a_{6} \cdot\left(\frac{B_{W L}}{T_{C}}\right)+a_{7} \cdot C_{P}+a_{8} \cdot C_{P}^{2}+a_{9} \cdot C_{P}^{3}
\end{aligned}
$$

Esta formulação da resistência adicional cobre os seguintes limites:

- Número de Froude entre 0.2 e 0.45;

- Ângulo de incidência de ondas entre 100 e 180 graus. De acordo com a convenção de ângulo de onda adotada, o ângulo é medido a partir da popa e, por exemplo, 180 graus corresponde a incidência de ondas pela proa;

- Raio de giração $\left(K_{y y}\right)$ entre 20 e $30 \%$ do comprimento do casco na linha d'água;

- Relação entre comprimento de onda e comprimento $\left(\lambda / L_{W L}\right)$ do navio entre 0.5 e 4.

Devido ao número de parâmetros que fazem parte de sua formulação, o resultado é um comportamento não-linear. O comportamento desta função e a influência de seus parâmetros pode ser analisado através de seu resultado para um veleiro com comprimento da linha d'água de 10 metros. No primeiro caso, apresentado na Figura 3, comparamos os valores da resistência adicional em ondas para diferentes ângulos de ondas e de raio de giração em função do comprimento de onda.

Como pode ser visto, comprimentos de onda menores (caso de águas abrigadas) aumentam significativamente a resistência adicional em ondas. Comprimentos de onda menores também levam a períodos reduzidos que podem se aproximar do período natural do casco, aumentando a amplitude do movimento e da resistência adicional em ondas. Contudo, não é possível afirmar que aumento na resistência adicional verificado seja causada por este efeito.

O mesmo procedimento pode ser aplicado para entender o efeito do ângulo de incidência da onda, como mostra a Figura 4. De forma geral, há um crescimento do efeito 
Figura 3 - Comparativo para comprimento de onda

Resistência adicional de ondas para diferentes parâmetros
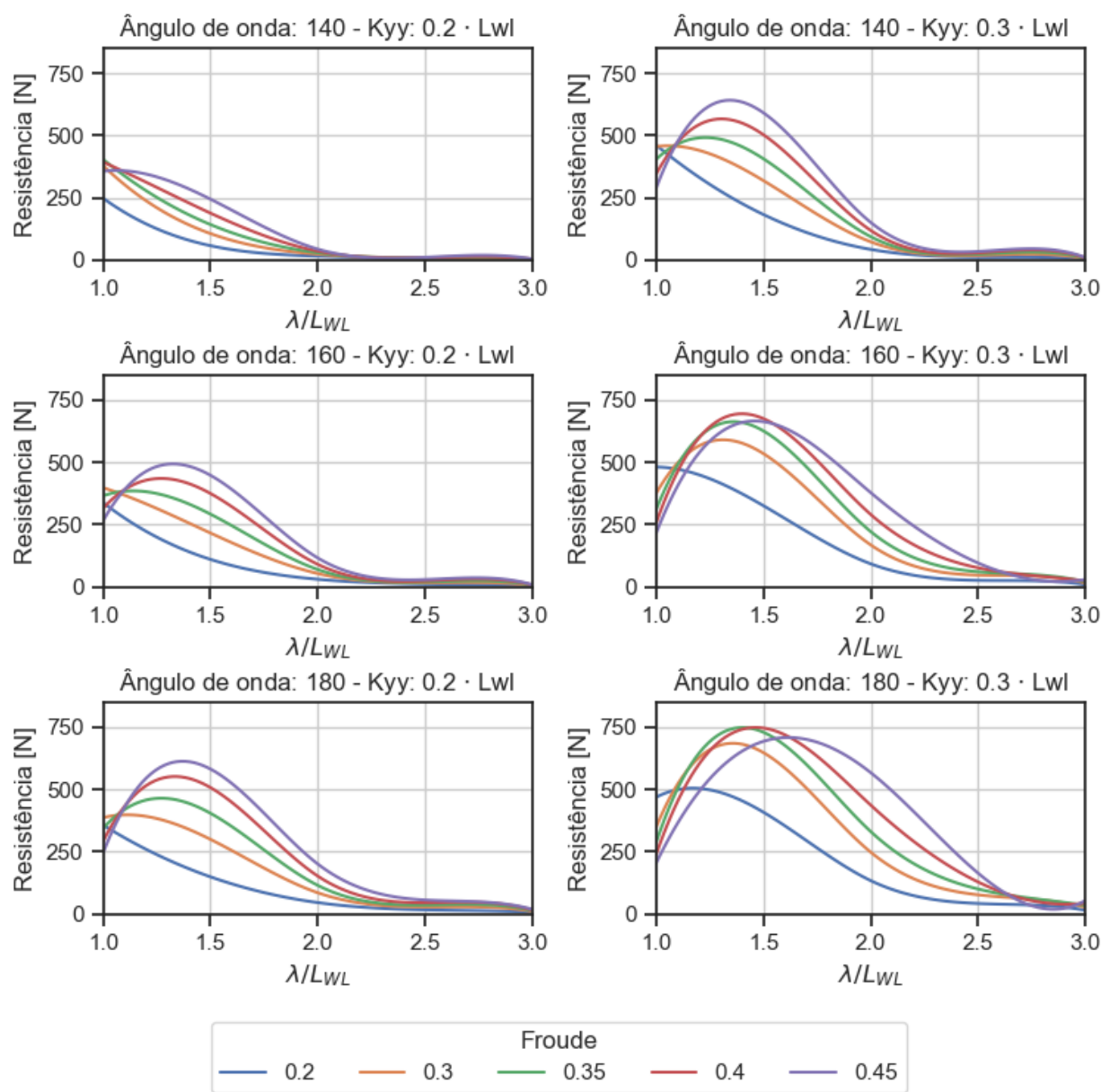

sobre a resistência adicional para ângulos de incidência maiores, com valores máximos a proa. Este efeito explica-se pela onda de proa ser longitudinal ao casco, enquanto a onda de través tem sua maior componente transversal ao plano de velocidade do casco.

O efeito do raio de giração sobre a resistência adicional pode ser analisado através de ambas figuras. A influência do raio de giração é grande sobre a resistência, como já apontava estudos preliminares como o de Keuning e Sonnenberg (1998). O raio de giração, portanto, deve apresentar valores idealmente baixos, como aponta Larsson e Eliasson (2001).

Há certa dificuldade em se avaliar a consistência dos resultados, uma vez que a resistência adicional em onda depende de vários parâmetros, entre eles os períodos naturais de pitch e heave. Além disso a resistência adicional em onda tem efeitos de segunda ordem em relação a resistência total. Entre os efeitos, uma parte se origina da alteração da área molhada, e outra dos efeitos de difração do casco, influenciada pelo movimento de pitch.

No entanto, para efeitos de comparação, utilizamos os resultados apresentados por Keuning, Vermeulen e Have (2006) quando comparando os valores obtidos por seu 
Figura 4 - Comparativo para ângulo de onda

Resistência adicional de ondas para diferentes parâmetros
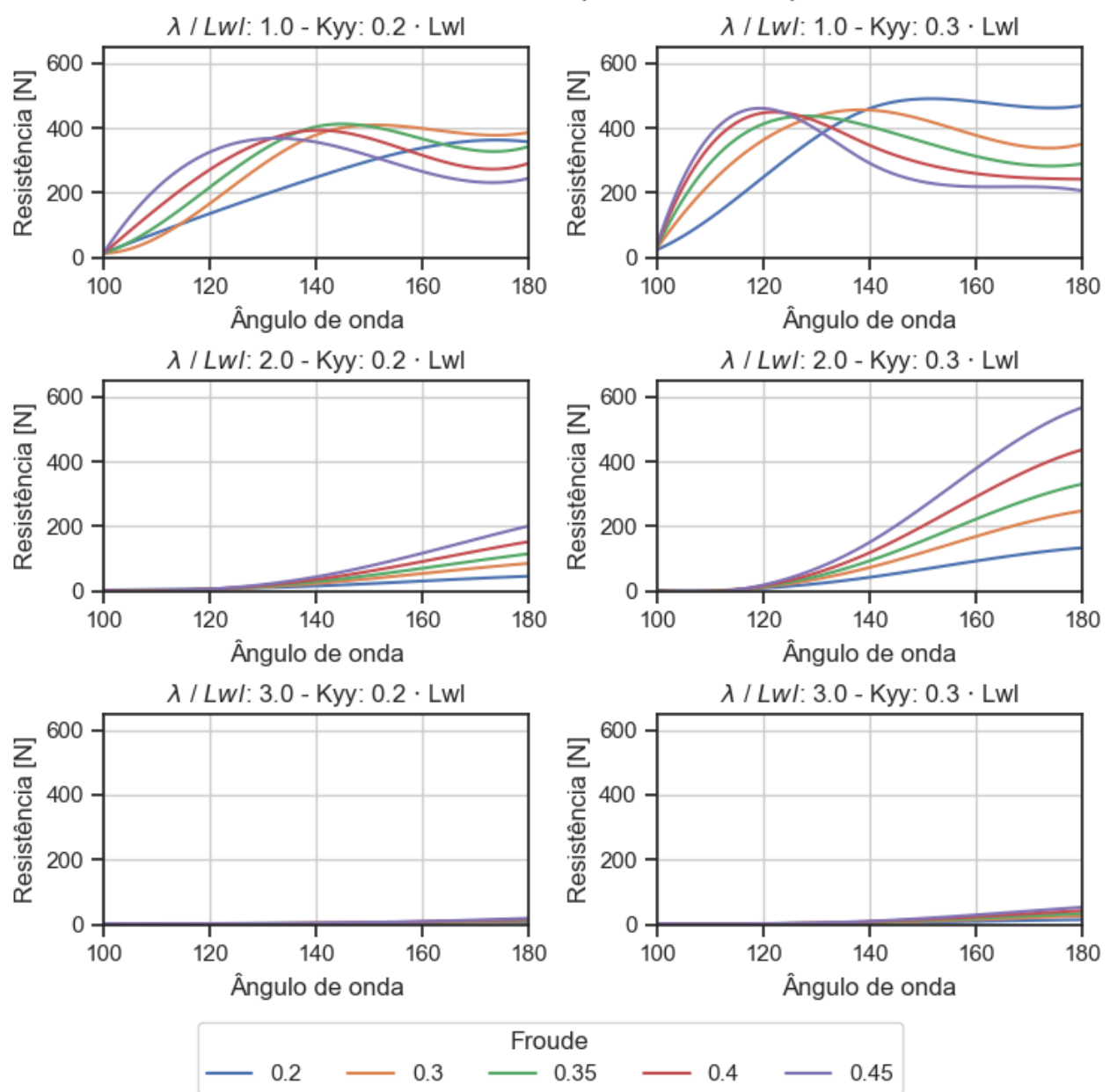

método com resultados provenientes de uma análise de teoria da faixas. Através da Figura 5 pode-se notar que há uma diferença para valores de frequência de onda maiores. Contudo, a curva assintótica do modelo implementado pode denotar que tenha havido uma mudança nos coeficientes da série deste sua publicação.

A resistência adicional em ondas ainda é afetada pelas obras-vivas, em especial a altura do costado, os balanços de popa e proa(LARSSON; ELIASSON, 2001). Contudo, estas dimensões afetam o desempenho de forma menos significativa, e portanto não entram como parâmetros na formulação de Delft.

A Equação (3.8), no entanto, pressupõe uma onda regular, o que não é representativo quando comparado a condições de mar. Em ondas irregulares, para um espectro de mar conhecido, o valor médio da resistência adicional em ondas pode ser calculado através o principio de superposição linear, dado na Equação (3.9).

$$
\bar{R}_{A W}\left(\omega_{e}\right)=2 \int_{0}^{\infty} \frac{R_{A W}}{\zeta_{a}^{2}} S_{\zeta}\left(\omega_{e}\right) d \omega_{e}
$$


Figura 5 - Comparativo com para ângulo de incidência de 140 graus

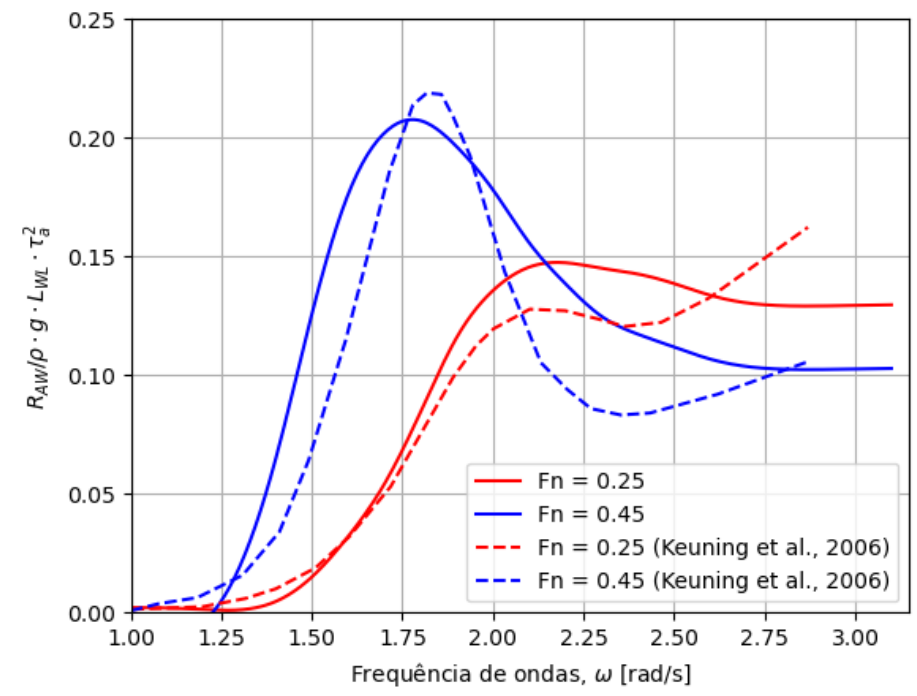

Onde $\zeta_{a}$ é a amplitude em metros, $S_{\zeta}$ é a densidade espectral em $m^{2} / s$ e $\omega_{e}$ a frequência de encontro em $\mathrm{rad} / \mathrm{s}$. A frequência de encontro considera o efeito da velocidade da embarcação $(V)$ e do ângulo de onda $(\beta)$ na frequência de onda e pode ser obtida através da Equação (3.10).

$$
\omega_{e}=\omega\left[1-V \frac{\omega}{g} \cos \beta\right]
$$

Para a densidade espectral, é adotado um espectro de Bretschneider, que propôs a seguinte formulação:

$$
S_{\zeta}\left(\omega_{e}\right)=0.1687 H_{s}^{2}\left(\frac{\omega_{s}^{4}}{\omega_{e}^{5}}\right) \exp \left\{-0.675\left(\frac{\omega_{s}^{4}}{\omega_{e}}\right)\right\}
$$

Onde $T_{s}$ é o período significativo do mar. Dessa forma, condições de mar passam a ser descritos através de período e altura significativa de onda.

\subsubsection{Resistência total}

A soma de todas estas componentes, ainda que analisadas separadamente, resulta na resistência ao avanço total do casco nu e pode de ser obtida através da Equação (3.12).

$$
R_{T}=R_{F}+R_{R}+R_{\text {incli }}+R_{A W}
$$

As diferenças em termos de magnitude das componentes pode ser observada através das Figuras 6 e 7, nas quais compara-se o primeiro casco-mãe da série de Delft, de deslocamento médio, com o casco Sysser 60, inserido na série recentemente, com deslocamento $50 \%$ menor. Os casco são comparados para um intervalo de número de 
Froude entre 0.2 e 0.45, com inclinação de 20 graus, altura significativa de onda de 1 metro, período significativo de 6 segundos, e ângulo de incidência de 180 graus (de proa), com raio de giração de $20 \%$ o comprimento do casco.

Figura 6 - Componentes da resistência para o casco Sysser 1

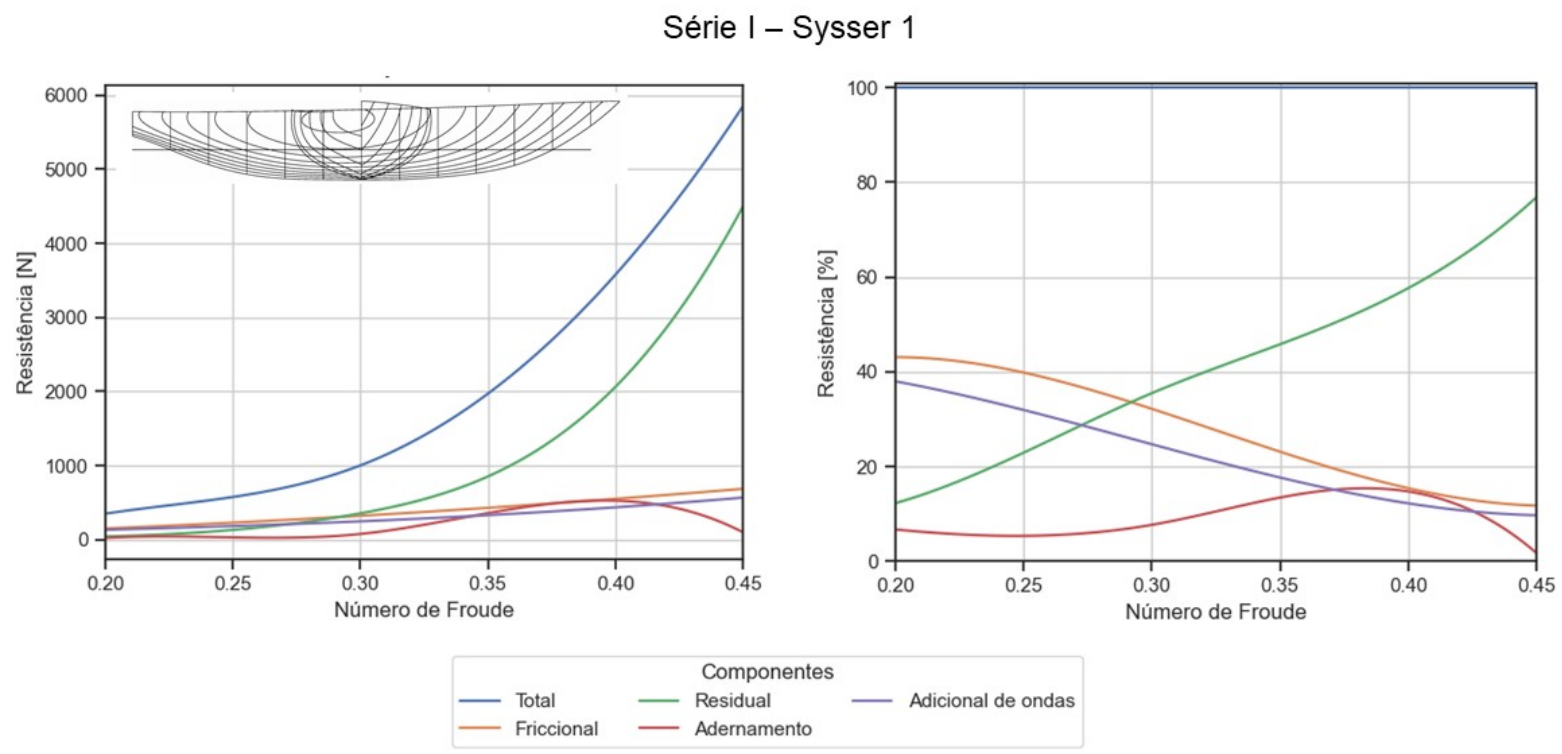

Figura 7 - Componentes da resistência para o casco Sysser 60

Série $\mathrm{VI}$ - Sysser 60

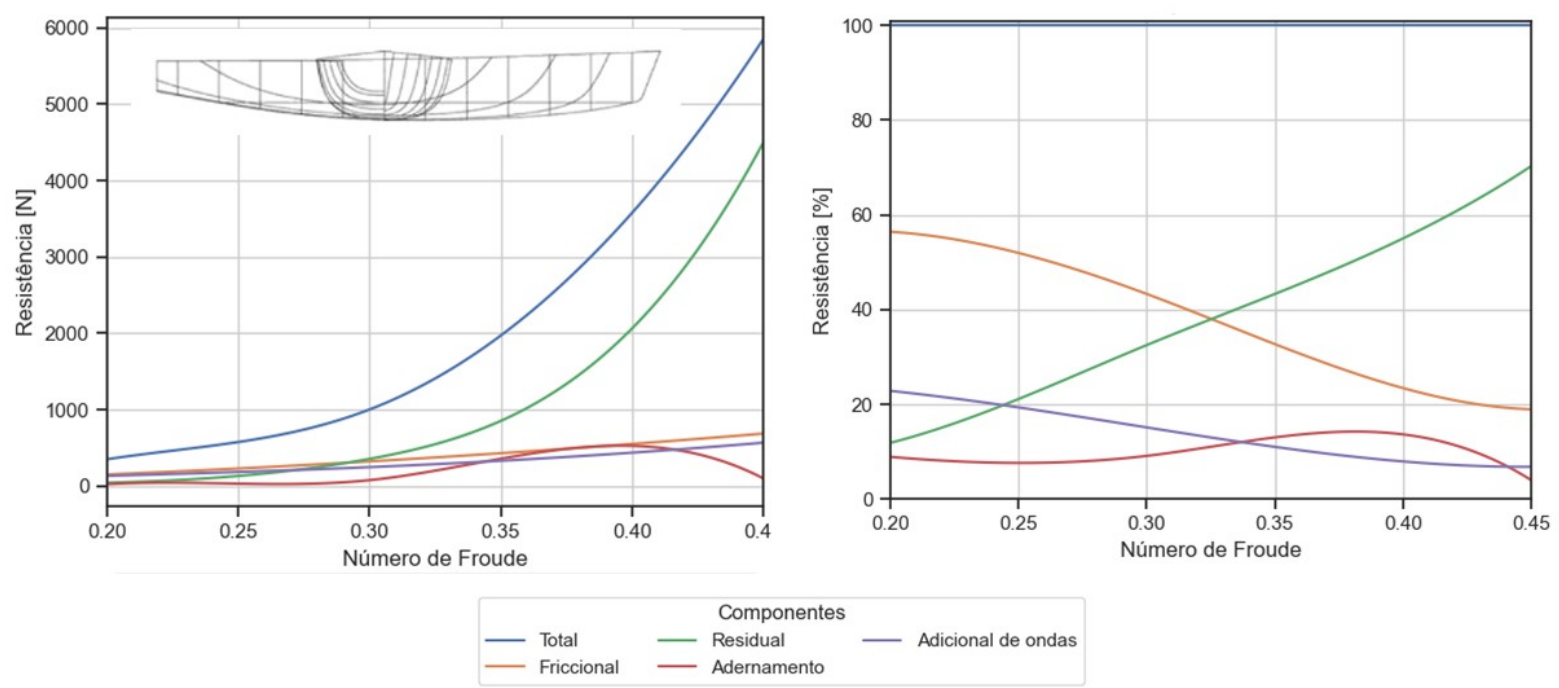

O que pode ser observado é o efeito dominante da resistência friccional agindo na interface água-casco em velocidades menores. Com o aumento da velocidade da embarcação, a resistência de onda aumenta significativamente e passa a ser a componente predominante devido a geração de ondas cada vez maiores. Já as componentes de resistência adicional 
em onda e devido ao adernamento usualmente possuem valores que orbitam entre $10 \%$ e $20 \%$ da resistência total para Froudes maiores que 0.3.

Para um veleiro mais delgado, como o Sysser 60, a dinâmica é semelhante, porém a resistência adicional em ondas tem efeito relativamente menor se comparada a um casco de maior deslocamento devido a influência que o valor da boca na linha d'água possui na componente da resistência adicional em onda.

\subsection{Técnicas de otimização}

Esta seção descreve a aplicação de algoritmo genéticos que buscam otimizar a resistência hidrodinâmica do casco nu. Os algoritmos genéticos, em geral, possuem um procedimento interno semelhante independentemente do método adotado, cujas etapas fundamentais são apresentadas na Figura 8.

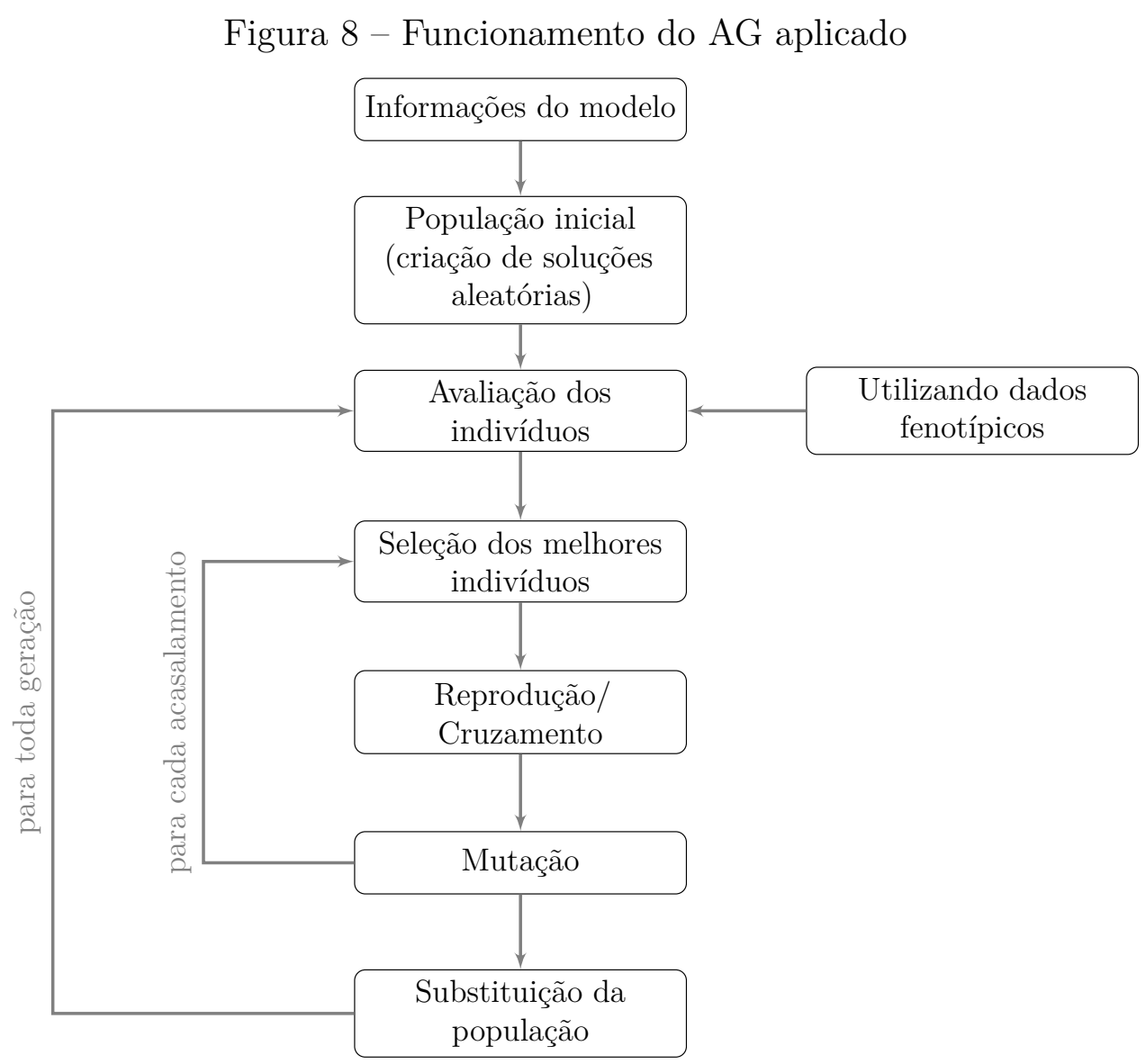

Fonte: Adaptado de Nelson, Kierczak e Carlborg (2013)

De acordo com Nelson, Kierczak e Carlborg (2013), cada uma destas etapas corresponde aos processos de:

- População inicial: corresponde a geração de indivíduos pseudo-aleatórios, contudo, dentro de limites do espaço amostral pré-estabelecidos pelo usuário; 
- Avaliação: toda solução é avaliada utilizando uma função de mérito. Neste caso, a resistência total do casco;

- Seleção: nesta etapa, os indivíduos mais aptos, nomeadamente aqueles com menor resistência total, são selecionados para serem combinados entre si. Em geral, recomenda-se empregar um método de seleção que permita explorar diferentes nichos do espaço amostral, reduzindo o risco de que a solução esteja presa a um mínimo local;

- Reprodução: promove a recombinação na qual certas partes de dois indivíduos são combinadas para gerar um novo indivíduo. Alguns métodos comumente utilizados são Partially-Mapped Crossover (PMX), Simulated Binary Crossover (SBX) e Bit Flip;

- Mutação: alguns dos novos indivíduos criados são selecionados para sofrerem mutação parcial em suas características;

- Substituição da população: os indivíduos criados substituem a população de indivíduos antigos.

Ainda que estas sejam as etapas essenciais de um algoritmo genético, outras podem ser adicionadas para criar características específicas que privilegiem certas aplicações em detrimento de outras, resultando em diferenças no tempo de convergência e capacidade de explorar o espaço de soluções. Tais diferenças são ilustradas na Figura 9 que apresenta os resultados para diferentes métodos aplicados a resolução do mesmo problema algébrico com o mesmo número de indivíduos gerados (1000).

Figura 9 - Comparativo entre diferentes algoritmos genéticos
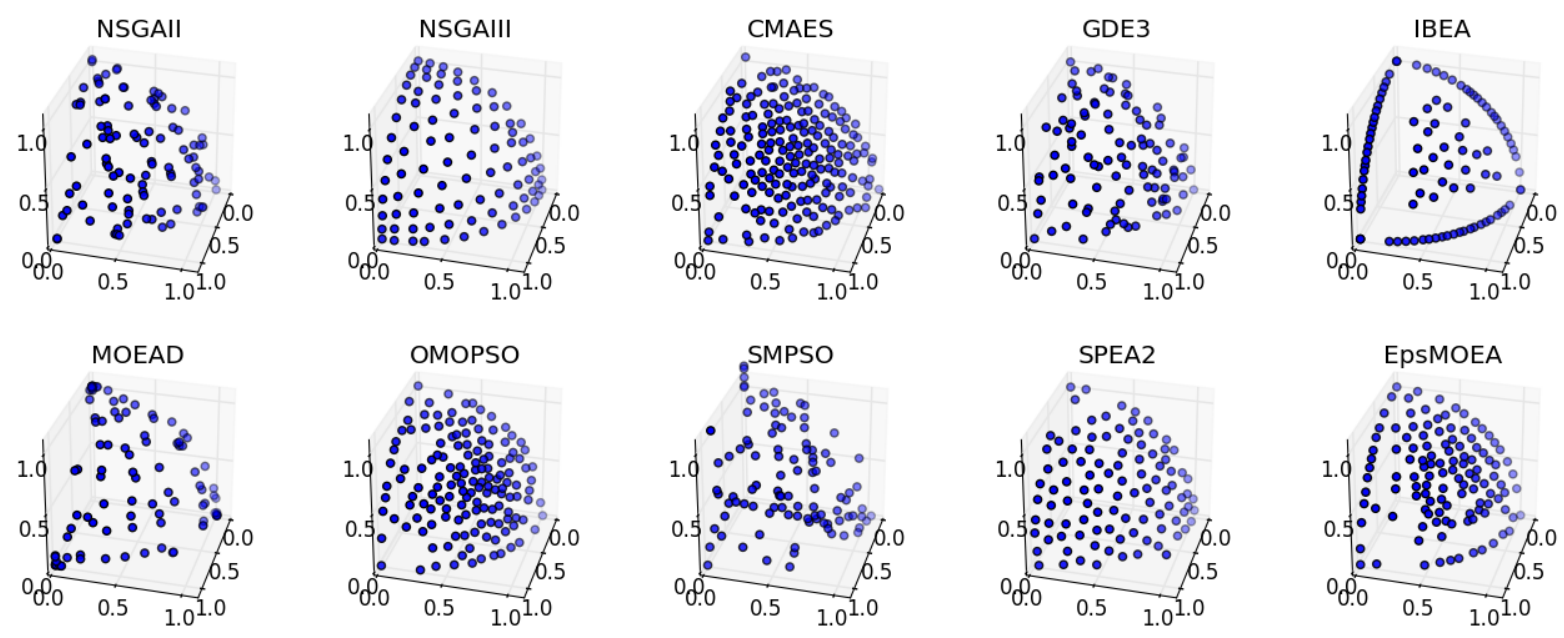

Fonte: Hadka e Reed (2013) 
É possível notar que o método NSGAIII maior dispersão na fronteira de pareto, similarmente ao SPEA2, que é fator decorrente das estratégias de nicho aplicadas em cada método. Ademais, outros três dados de entrada são essenciais para o funcionamento do algoritmo genético.

- Taxa de mutação;

- O número máximo de avaliações da função objetivo realizado, funcionando como critério de parada, ou a aplicação de um critério iterativo a partir do estimador de ótimo;

- Tamanho da população inicial gerada.

Quando adicionamos mais de um objetivo à análise de otimização, devemos considerar as possíveis relações de compromisso e suas implicações. Duas delas se destacam: o conceito de dominância de Pareto e o de fronteira de Pareto. A dominância ocorre quando duas soluções factíveis do problema devem ser comparadas em vista de funções de mérito, ou funções-objetvo. Por exemplo, dadas duas soluções $x$ e $y$, diz-se que $x$ domina $y$ se a solução $x$ é melhor ou igual a $y$ em uma ou todas as funções-objetivo. Já o conceito da fronteira de Pareto corresponde ao caso em que um objetivo não pode ser melhorado sem prejudicar um outro. A fronteiro de Pareto é um conceito desenvolvido pelo economista italiano Pareto (1964) que descreve o equilíbrio entre objetivos conflitantes representando este limite como uma região que concentra os indivíduos tidos como ideais, ou pareto-ótimos, em que a melhoria de um de seus objetivos afeta negativamente os demais. Portanto, o melhor indivíduo estará contido nesse conjunto, e sua escolha depende dos critérios estabelecidos pelo usuário. Desconhecendo quaisquer critérios para avaliar as soluções, todos os indivíduos pareto-ótimos são igualmente importantes.

De acordo com Ticona (2003), duas características devem ser observadas em processos de otimização multiobjetivo:

- Proximidade com a Fronteira de Pareto: o conjunto de soluções ideais é aquele que se encontra mais próximo da Fronteira;

- Diversidade: deve-se buscar a maior diversidade possível no espaço explorado dos objetivos. 


\section{Capítulo 4}

\section{Metodologia do processo de otimização}

A metodologia adotada no processo de otimização se enquadra, de acordo com a classificação proposta por Gil (2002), como uma Pesquisa Experimental. Este tipo de pesquisa é definido como aquele em que se parte de um objeto de estudo para analisar as variáveis capazes de influencia-lo, sendo que formas de controle são impostas para realizar as observações dos efeitos que cada variável produz no objeto de estudo. Quando falamos em objeto de estudo, nos referimos ao casco do veleiro analisado, sob efeito das suas variáveis, ou seja, suas dimensões principais.

A estratégia adotada para a realização deste estudo se dá através da aplicação de algoritmos genéticos ao cálculo da resistência hidrodinâmica do casco nu de um veleiro com o objetivo de obter as dimensões do casco que produzem a menor resistência hidrodinâmica (e portanto maior velocidade) enquanto satisfazem restrições de segurança e conforto.

Para definir os conceitos básicos deste problema, este capítulo é estruturado da seguinte forma:

- Variáveis do processo de otimização;

- Função objetivo;

- Restrições do problema.

\subsection{Variáveis do processo de otimização}

As variáveis de projeto correspondem as dimensões utilizadas para o cálculo das componentes da resistência hidrodinâmica pela série de Delft ou para o cálculo de coeficientes de segurança e conforto, estas últimas opcionais. Neste estudo as dimensões são 
variáveis contínuas que representam a forma do casco através de dimensões básicas e de coeficientes de formas, listados na Tabela 1.

Tabela 1 - Dimensões dos veleiros utilizados no processo

\begin{tabular}{lccl}
\hline Dimensões & & Unidade & Componentes da resistência \\
\hline Boca na linha d'água & $B_{W L}$ & $\mathrm{~m}$ & $R_{F}, R_{R}, R_{\text {incli }}, R_{a w}$ \\
Calado moldado & $T_{C}$ & $\mathrm{~m}$ & $R_{F}, R_{R}, R_{\text {incli }}, R_{a w}$ \\
Centro de flutuação & $\mathrm{LCF}^{1}$ & $\%$ & $R_{R}$ \\
Centro de carena & $\mathrm{LCB}^{1}$ & $\%$ & $R_{R}, R_{\text {incli }}$ \\
Coeficiente de bloco & $C_{B}$ & - & $R_{R}, R_{a w}$ \\
Coeficiente do plano d'água & $C_{W P}$ & - & $R_{R}$ \\
Coeficiente prismático & $C_{P}$ & - & $R_{R}, R_{a w}$ \\
Coeficiente da seção mestra & $C_{M}$ & - & $R_{F}, R_{\text {incli }}$ \\
\hline
\end{tabular}

Outras dimensões que fazem parte da análise mas não são variáveis no projeto de otimização são listas abaixo. Estas dimensões são utilizadas na série de Delft, porém obtidas através do coeficiente de forma para evitar conflito entre os dois.

- Comprimento na linha d'água $\left(L_{W L}\right)$ : mantido fixo ao longo do processo para que a comparação seja feita entre cascos com características semelhantes. Para o caso de veleiros aqui investigados, comprimento é um melhor indicador de porte da embarcação do que o deslocamento;

- Área do plano d'água $\left(A_{W P}\right)$ : calculada através das dimensões básicas e do coeficiente do plano d'água;

- Deslocamento: calculado como função das dimensões básicas e do coeficiente de bloco;

- Boca máxima $\left(B_{O A}\right)$, comprimento total $\left(L_{O A}\right)$ e razão de lastro: utilizado no cálculo dos fatores de segurança;

- Ângulo de incidência de ondas $(\theta)$, altura significativa de ondas $\left(H_{S}\right)$, período de pico $\left(T_{P}\right)$ e raio de giração $\left(K_{Y Y}\right)$ : utilizados no cálculo da resistência adicional em ondas.

\subsection{Função objetivo}

A função objetivo adotada procura representar duas características essenciais no projeto de veleiros: velocidade e segurança na navegação, representadas através da

1 Medidos a partir da seção mestra como porcentagem do comprimento da linha d'água e positivos à vante 
resistência hidrodinâmica total em águas calmas $\left(R_{T}\right)$ e da resistência adicional em onda $\left(R_{A W}\right)$.

A primeira análise é a resistência desconsiderando o efeito em ondas. Contudo, como o veleiro é sujeito a diversas condições de operação, utilizamos como função objetivo a integral da resistência para um intervalo de Froude (entre $i$ e $j$ ) e um intervalo de inclinação (entre $k$ e $l$ ), como mostra a Equação (4.1). Este tipo de análise não é usual no projeto de veleiros, onde o projetista procurar dimensionar a embarcação tendo em vista o desempenho em uma faixa de Froude preferencial. Para este tipo de análise, basta restringir o intervalo para um único valor.

$$
F_{1}=\sum_{F n=i}^{j} \sum_{\phi=k}^{l} R_{T}(F n, \phi)
$$

Alternativamente, pode-se avaliar a resistência em diferentes condições de mar. Pata tal, utilizamos a soma da resistência total e da resistência adicional multiplicados pelas constantes $a_{1}$ e $a_{2}$. Estes coeficientes permitem atribuir diferentes pesos a estas componentes ou pesos iguais, quando ambos são iguais a 1. Esta característica permite a busca por cascos com melhor desempenho relativo em condições adversas de mar, por exemplo.

$$
F_{2}=\sum_{F n=i}^{j} \sum_{\phi=k}^{l} a_{1} R_{T}(F n, \phi)+a_{2} R_{A W}\left(F n, H_{S}, T_{P}, K_{y y} / L_{W L}, \theta\right)
$$

\subsection{Restrições}

Ao longo do processo de otimização, o número de cascos gerados e analisados não permite que sua viabilidade seja verificada manualmente a cada iteração. A viabilidade pode ser afetada por aspectos como a manufatura do casco ou o equilíbrio de forças do casco, por exemplo. Portanto, para garantir que o resultado seja viável, algumas restrições devem ser aplicadas para delimitar o espaço amostral. As restrições incluídas no modelo incluem:

- Restrições dimensionais do modelo;

- Restrições de segurança;

- Restrições de conforto.

\subsubsection{Restrições do modelo}

A série sistemática de Delft utilizada no cálculo da resistência ao avanço tem aplicado ao longo do desenvolvimento dos seus modelos em escala variações em oito razões 
adimensionais, respeitando certos limites, listados na Tabela 2. Dessa forma, não atender estes limites corresponde a diminuir a confiabilidade dos resultados do modelo. Para evitar este problema, tais razões foram aplicadas como restrições do modelo.

Tabela 2 - Restrições adimensionais da série sistemática

\begin{tabular}{lccc}
\hline Relação & Adimensional & Mínimo & Máximo \\
\hline Comprimento - boca & $\frac{L_{W L}}{B_{W L}}$ & 2.73 & 5.0 \\
Boca - calado & $\frac{B_{W L}}{T_{C}}$ & 2.46 & 19.38 \\
Boca - deslocamento & $\frac{L_{W L}}{\nabla_{c}^{13}}$ & 4.34 & 8.5 \\
Fator de carga & $\frac{A_{W}}{\nabla_{c}^{23}}$ & 3.78 & 12.67 \\
Centro longitudinal de carena & $\mathrm{LCB}$ & $-8.2 \%$ & $0 \%$ \\
Centro longitudinal de flutuação & $\mathrm{LCF}$ & $-9.5 \%$ & $-1.8 \%$ \\
Coeficiente prismático & $C_{P}$ & 0.52 & 0.65 \\
Coeficiente da seção mestra & $C_{M}$ & 0.65 & 0.78 \\
\hline
\end{tabular}

Fonte: Keuning e Sonnenberg (1998)

Além destas restrições, há uma observação importante a se fazer em relação ao deslocamento que também pode atuar como restrição. As funções de resistência (total e adicional em ondas) aplicadas ao modelo como função objetivo são diretamente proporcionais ao deslocamento do casco. Portanto, espera-se que durante o processo o deslocamento do casco diminua gradativamente enquanto as demais restrições forem atendidas.

Para evitar que ocorra um adelgamento acentuado do casco, ao ponto de que o espaço interno impossibilite a instalação do arranjo interno, o deslocamento é definido como uma restrição. Esta restrição pode ser ajustada pelo usuário na ferramenta desenvolvida, visando um espaço interno mínimo ou um deslocamento previamente estipulado para

\subsubsection{Restrições de segurança}

Realizar estimativas referentes a segurança, emborcamento e inundação é mais impreciso, dentro deste contexto, do que estimar a velocidade final desempenhada pela embarcação. Tal fato se dá pela necessidade de saber de antemão a forma do convés e sua própria estrutura interna, como anteparas estanques, por exemplo.

Uma alternativa seria o uso da Curva de Estabilidade Estática (CEE). A CEE mostra a resistência ao emborcamento para diversos ângulos de banda do casco, representando dessa forma o quão fácil ou difícil é emborcar uma embarcação. Todavia, o detalhamento 
necessário para a estimativa da CEE é incompatível com a etapa a que se destina essa ferramenta.

Uma solução para este dilema é utilizar-se de outros fatores mais simples de calcularse, ainda que mais implícitos. O primeiro deles é o Ângulo de Perda de Estabilidade. Uma forma de calculá-lo sem recorrer ao cálculo de GZ para diversos ângulos é através do Método de Estabilidade de Wolfson (DEAKIN, 1991). O fator proposto por Wolfson foi desenvolvido para classificar veleiros em termos de quais teriam quesitos de segurança indubitavelmente satisfatórios. Sua formulação leva em contas regressões com banco de dados que apontaram uma forte correlação entre estabilidade e a razão entre Boca $\left(B_{O A}\right)$ e Calado $\left(T_{C}\right)$. Para adimensionalizar a unidade, a raiz cúbica do deslocamento foi adicionada. Para incorporar os efeitos do centro de gravidade, optou por incluir a Razão de lastro (BR). O fator de Wolfson para perda de estabilidade é dada pela Equação (4.3).

$$
\phi_{V}=110+\left(\frac{400}{S S V-10}\right)
$$

No qual o índice SSV (Screening Stability Value) é dado pela Equação (4.4). Uma observação importante é que o calado é medido a partir da distância da linha de centro contando $1 / 8$ do valor da boca máxima. Para efeitos de simplificação, usualmente adota-se $90 \%$ do valor do calado.

$$
S S V=\frac{B_{O A}{ }^{2}}{B R \cdot T_{C} \cdot \nabla_{c}^{1 / 3}}
$$

Através das equações acima é possível entender que o aumento da boca incide em uma diminuição do Ângulo de Perda de Estabilidade. Em contrapartida, o aumento do calado e do deslocamento fará com que o Ângulo de Perda de Estabilidade aumente também. Dessa forma, conclui-se que este objetivo irá priorizar cascos com aspecto mais delgado. De forma geral, a regra adotada é de que o ângulo de perda de estabilidade seja de 120 graus ou mais para embarcações com menos de 75 pés, valor este que é implementado como restrição neste trabalho.

O segundo parâmetro passível de ser calculado é o Fator de emborcamento (Capsize Screening Factor - CS) que estima de forma simplificada a energia (dos ventos ou ondas) necessária para emborcar ou desemborcar um casco (ROUSMANIERE, 1987). Evidentemente, quanto maior a embarcação, maior a energia necessária para emborca-la. O valor de CS é definido pela Equação (4.5) e depende exclusivamente da boca máxima em pés e deslocamento em massa dado em libras. Quanto menor o seu valor, mais resiliente a 
embarcação é em relação ao emborcamento.

$$
C S=\frac{B_{O A}}{\left(\frac{\Delta_{c}}{64}\right)^{1 / 3}}
$$

Este fator foi resultado das embarcações participantes da regata Fastnet em 1979. Devido ao mau tempo, diversos veleiros emborcaram ao longo da competição. Os poucos que permaneceram intactos foram aqueles com um CS inferior a 2. Este valor é utilizado como pré-definido na ferramenta, permitindo que o usuário modifique em busca de soluções alternativas. Atualmente, este valor é aceitável para veleiros em geral. Este índice se comporta de forma muito semelhante ao Ângulo de Perda de Estabilidade, em que o aumento da boca e a diminuição do deslocamento influenciam negativamente a avaliação final.

\subsubsection{Restrições de conforto}

O conforto proporcionado por um veleiro é também um índice subjetivo de ser avaliado. Contudo, uma abordagem possível é mensurar as acelerações verticais quando atingido por ondas, responsáveis em grande parte pelo desconforto da tripulação.

Uma forma de medir tal sensação em veleiros foi proposta por Brewer (1985) através da Razão de conforto em movimento (Motion Comfort Ratio - MCR). Este índice é uma estimativa da restauração da embarcação em pitch quando a embarcação é acometida por ondas. A restauração é proporcional as acelerações angulares, que fazem a embarcação por sua vez alcançar velocidades maiores, todavia à custa do desconforto dos tripulantes.

O índice MCR resulta dos valores de deslocamento em massa dado em libras, boca no convés em pés $\left(B_{O A}\right)$ e do comprimento da embarcação na linha d'água em pés $\left(L_{W L}\right)$ e total em pés $\left(L_{O A}\right)$.

$$
M C R=\frac{\Delta_{c}}{\left(B_{O A}{ }^{4 / 3}\right) \cdot 0.65 \cdot\left(0.7 \cdot L_{W L}+0.3 \cdot L_{O A}\right)}
$$

Dessa forma, são privilegiadas embarcações com maiores overhangs e bocas mais estreitas. Além desse fator, é possível estimar as acelerações verticais de veleiros de acordo com Marchaj (1964). Embora ambos os índices estejam intrinsecamente relacionados, este, não considera valores de comprimento total, mas somente a boca máxima em pés e calado.

$$
R A=\left(\frac{6.28}{T_{C}}\right)^{2} \cdot\left(B_{O A}-1.5\right) \cdot \frac{10 \cdot \pi}{180 \cdot 32.2}
$$

Valores de RA menores que $0.06 g$ são recomendados. Acelerações maiores que $0.4 \mathrm{~g}$ são insuportáveis mesmo que por curtíssimos períodos de tempo, onde $g$ é a aceleração 
da gravidade. Em suma, os três critérios de conforto e segurança adotas são listados na Tabela 3 .

Tabela 3 - Restrições de segurança e conforto

\begin{tabular}{lc}
\hline Índice & Valor máximo \\
\hline Fator de Wolfson $\left(\phi_{V}\right)$ & 120 graus \\
Fator de emborcamento (CS) & 2 \\
Aceleração vertical (RA) & $0.59 \mathrm{~m} / \mathrm{s}^{2}$ \\
\hline
\end{tabular}

\subsection{Algoritmo de otimização}

O processo de otimização é aplicado através de algoritmos genéticos, mais especificamente o NSGAII, cujo funcionamento foi descrito no capítulo anterior. A operação deste algoritmo depende de quatro parâmetros que podem afetar o tempo de processamento e a qualidade da resposta, listados na Tabela 4 juntamente com os valores sugeridos pela ferramenta desenvolvida.

Tabela 4 - Parâmetros principais do algoritmo

\begin{tabular}{lc}
\hline Parâmetro & Valor padrão \\
\hline Tamanho da população inicial & 100 \\
Taxa de reprodução & $75 \%$ \\
Taxa de mutação & $10 \%$ \\
Número de gerações & 1000 \\
Critério de convergência & $0.001 \%$ \\
\hline
\end{tabular}

De forma geral, aumentar o tamanho da amostragem inicial permite que o espaço amostral seja explorado de forma mais completa e uniforme. Similarmente, as taxas de mutação e reprodução quando maiores permitem que soluções mais diversas sejam desenvolvidas ao longo do processo evitando o risco de mínimos locais. Por último, o número de gerações, que determina a quantidade de iterações ao longo do processo, pode ser usado como alternativa para o critério de convergência. No primeiro caso, o processo se encerra após um determinado número de iterações, sem levar em conta a qualidade do resultado. Já no segundo caso, o processo se encerra quando um determinado número de iterações não é capaz de gerar melhorias maiores que um certo critério. A depender do critério adotado, há o risco de convergir-se à um mínimo local. 



\section{Capítulo 5}

\section{Ferramenta desenvolvida}

Entre os objetivos propostos nesta dissertação, está o desenvolvimento de uma ferramenta baseada na metodologia apresentada no capítulo anterior. Esta ferramenta, SailPy, é disponibilizada online ${ }^{1}$ e, sendo esta sua primeira versão, se destina ao uso acadêmico. Para tanto, uma interface gráfica foi desenvolvida para facilitar o uso e estimular futuras contribuições através de seu repositório Git.

Esta ferramenta foi estruturada de forma linear através de quatro etapas pelas quais o usuário progride, partindo de uma concepcão inicial e finalizando em um casco recomendado pelo programa com uma estimativa de desempenho. Inicialmente, o usuário pode fazer uma análise prévia de como as dimensões no projeto preliminar afetam diferentes componentes da resistência hidrodinâmica. Após decidir o conjunto de dimensões que melhor atende seus requisitos, o usuário pode aplicar um estudo de otimização através de algoritmos genéticos que eventualmente podem indicar melhorias na forma do casco. $\mathrm{O}$ conjunto de cascos gerados neste processo é apresentado na página seguinte, permitindo que usuário escolha o casco que melhor atende suas necessidades. Na última parte da ferramenta, o usuário pode avaliar como o desempenho do casco com apêndices e velame através de um VPP (Velocity Prediction Program).

Este capítulo apresenta o resultado do desenvolvimento e descreve o funcionamento da ferramenta em maiores detalhes.

\subsection{Página 1: Introdução}

A primeira página apresenta o funcionamento da ferramenta ao usuário através de seis etapas seguida de uma descrição mais detalhada visando familiarizar o usuário com o que esperar ao final da aplicação.

1 sailapp.herokuapp.com 
Figura 10 - Página introdutória

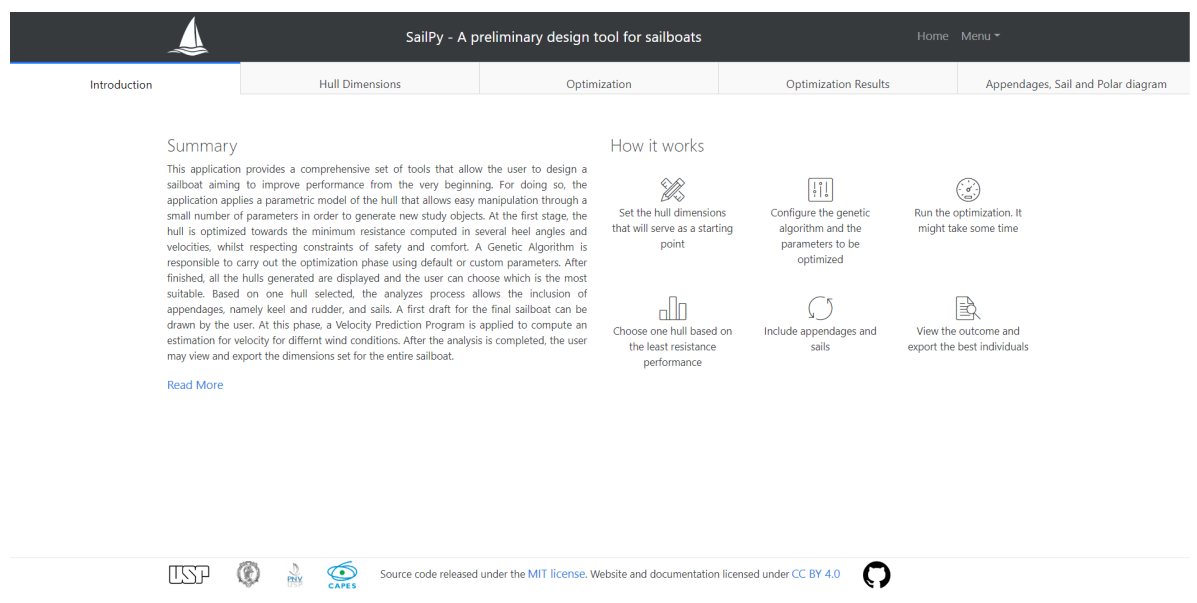

\subsection{Página 2: Dimensões iniciais}

O processo de análise do usuário inicia com a avaliação das dimensões básicas do casco e a resistência hidrodinâmica resultante. A página é estruturada visando a permitir a comparação de dois cascos diferentes. O intuito é incentivar um processo racional do projeto do casco, relacionando o efeito de alterar as dimensões do casco nas diferentes componentes hidrodinâmicas do casco.

Figura 11 - Análise preliminar

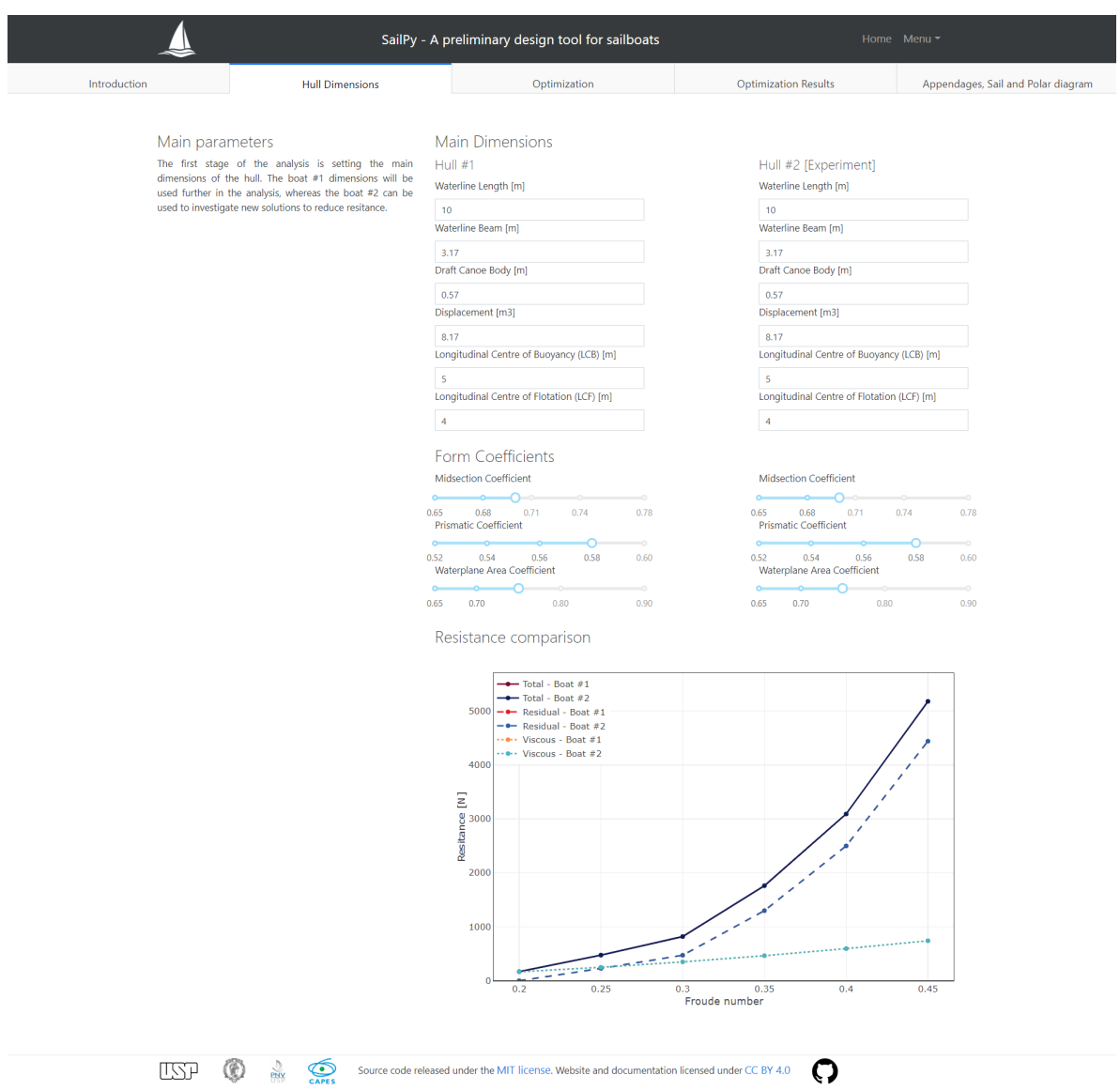




\subsection{Página 3: Definir o escopo da otimização}

De posse de uma estimativa inicial das dimensões principais do casco, o usuário pode investigar possíveis melhorias no desempenho do casco. Para tal, um algoritmo genético é responsável por sistematizar este processo e avaliar milhares de soluções de forma orientada e sistêmica. O algoritmo genético é implementado através da biblioteca DEAP (Distributed Evolutionary Algorithms in Python) (FORTIN et al., 2012) disponível para Python.

O tipo de algoritmo genético a ser aplicado pode ser escolhido dentre seis alternativas, sendo o NSGAII o mais recomendado. Para o estudo do casco, o usuário pode escolher entre uma otimização mono-objetivo, analisando apenas a resistência total hidrodinâmica para uma dada condição de mar, ou uma otimização multi-objetivo que avalia as componentes da resistência em águas calmas e adicional em ondas.

Figura 12 - Definição do problema e configuração da otimização

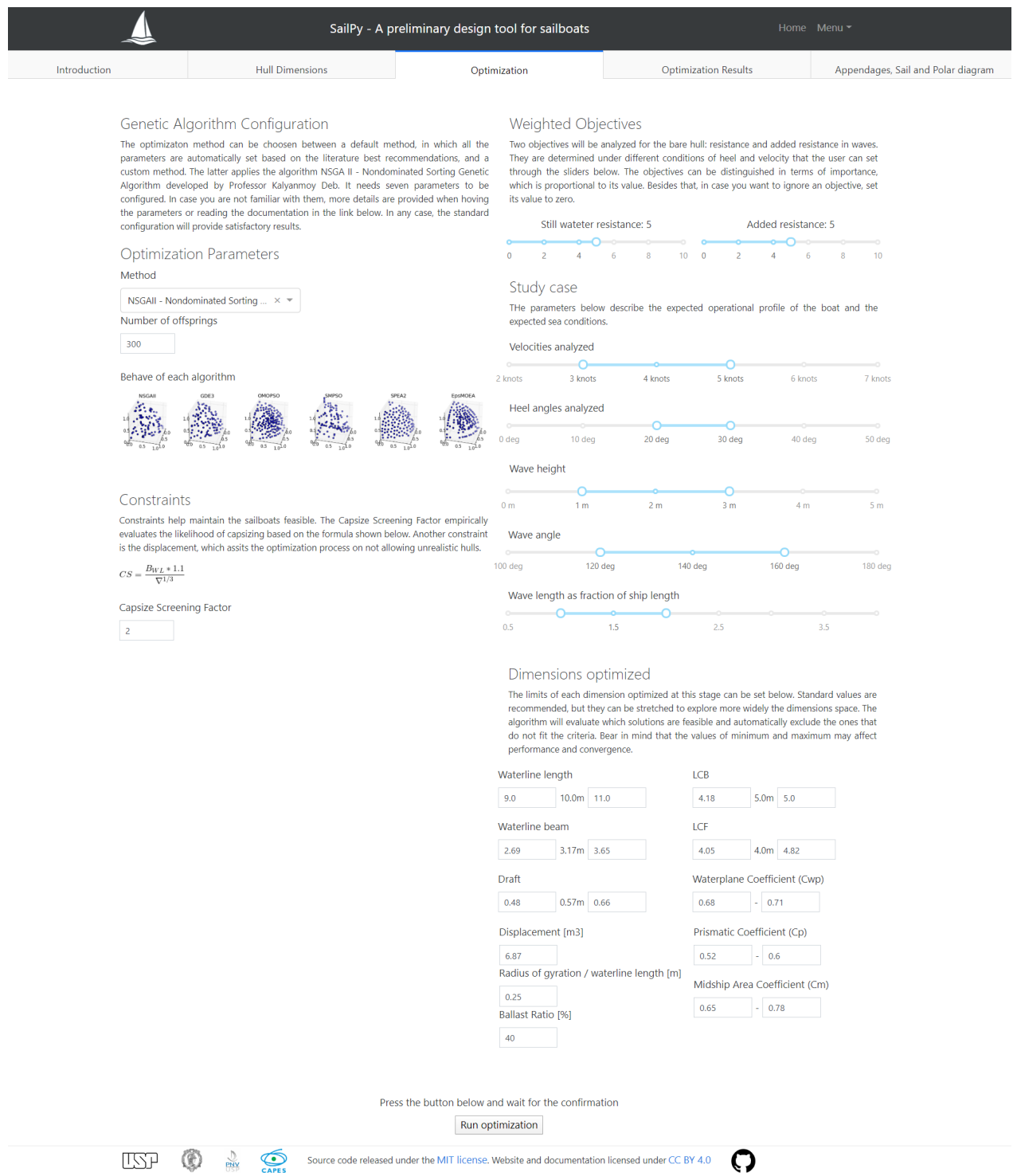


A depender do tipo de aplicação destinada ao veleiro projetado, o usuário pode ajustar as condições de mar esperadas através de parâmetros como comprimento e altura de onda.

Por último, o usuário pode definir as dimensões máximas e mínimas desejadas e que serão exploradas pelo algoritmo genético. Dentro deste espaço, a solução inicial proposta pelo usuário não é diretamente incluída e serve apenas para comparação ao final do processo. Se o intervalo for excessivamente alto ou conflitante com os limites da série de Delft, o casco será desqualificado do processo de otimização. Resultados satisfatórios são obtidos com 1000 cascos analisados, mas um número maior é recomendado para uma análise com maio grau de confiança.

\subsection{Página 4: Resultados preliminares}

Os resultados do problema estabelecido na página anterior são apresentados nesta página. O usuário pode avaliar os valores alcançados pelo objetivo otimizado em função das mudanças nas dimensões. No caso de dois objetivos, é possível visualizar a fronteira de Pareto. Os pontos em vermelho representam os cascos que infringiram uma ou mais restrições de projeto, enquanto os demais pontos apresentam cores que indicam em que iteração do algoritmo genético eles foram gerados, de acordo com a escala ao lado.

Figura 13 - Resultado preliminar

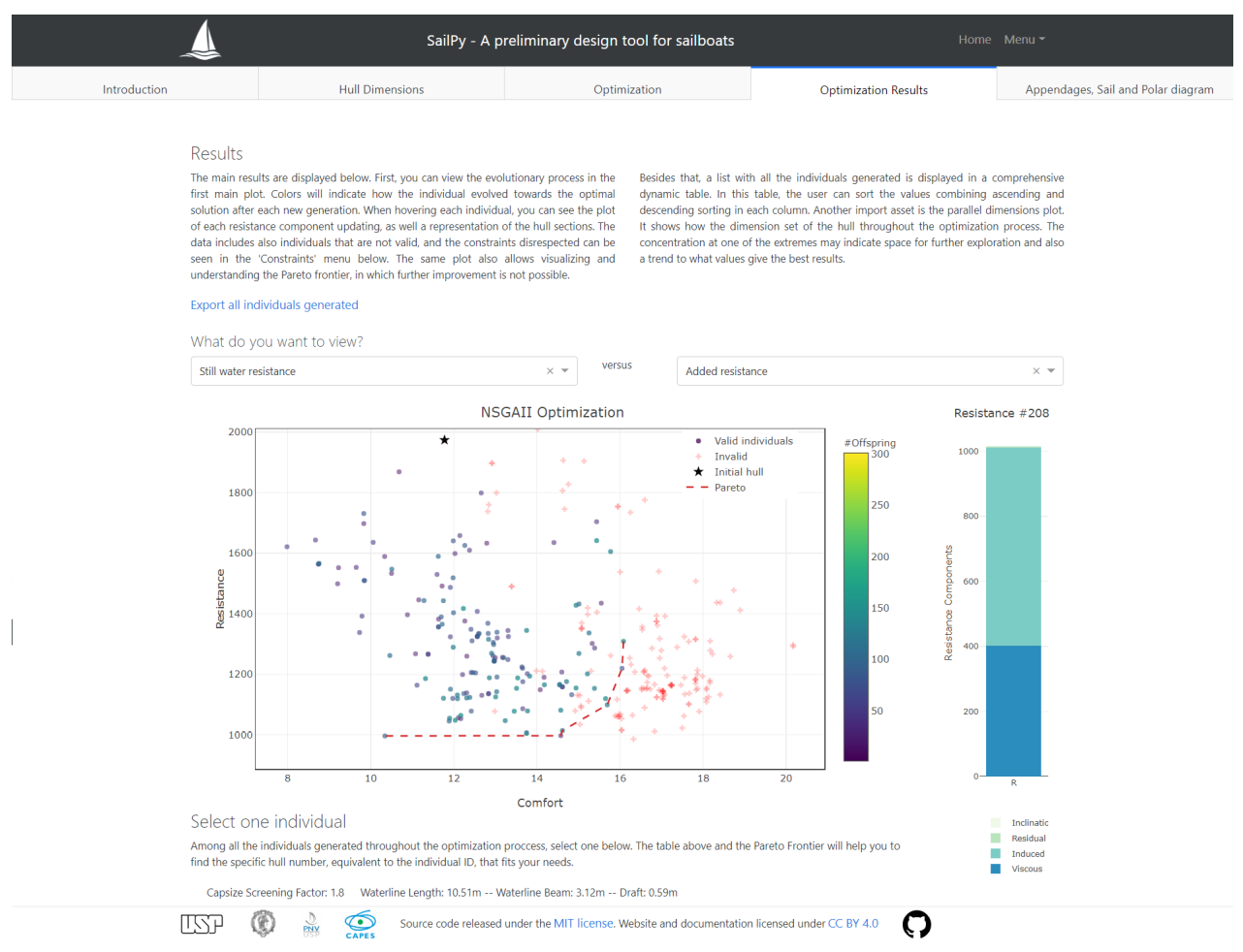

Alterando as opções de visualização, o usuário também pode investigar como as dimensões se comportaram durante o processo de otimização. Uma investigação mais 
detalhada pode ser realizada ao exportar todos os cascos gerados durante o processo em uma planilha contendo as dimensões do casco, valores de resistência e restrições infringidas.

O usuário pode escolher um dos cascos que mais se adequa aos objetivos do projeto e analisar o seu desempenho na página seguinte.

\subsection{Página 5: Avaliação com apêndices e velames}

Na etapa final da ferramenta, estimativas de velame, quilha e leme são adicionados ao casco nu com base nas regressões realizadas pelo trabalho de Simos, Illuminati e Prado (2007), contudo, ainda permitindo que o usuário realize modificações tendo em vista seu projeto. Caso o usuário tenha em mente as dimensões que deseja utilizar, uma representação iterativa do perfil do veleiro é mostra e se ajusta as dimensões inseridas.

Para avaliar o desempenho final do veleiro, a ferramenta utiliza um VPP para estimar o desempenho em diferentes condições de vento através de um diagrama polar. O VPP foi desenvolvido no Departamento de Engenharia Naval e Oceânica da Escola Politécnica da USP e sua mais recente versão contém aprimoramento na predição da velocidade (KANTOROWITZ, 2019).

Caso o usuário não esteja satisfeito com o resultado, é possível retornar à uma etapa anterior e alterar os parâmetros analisados em busca de uma solução mais adequada.

No próximo capítulo, temos um estudo de caso utilizando a ferramenta aqui apresentada em uma análise de otimização de cinco cascos de características diferentes. 
Figura 14 - Análise de desempenho

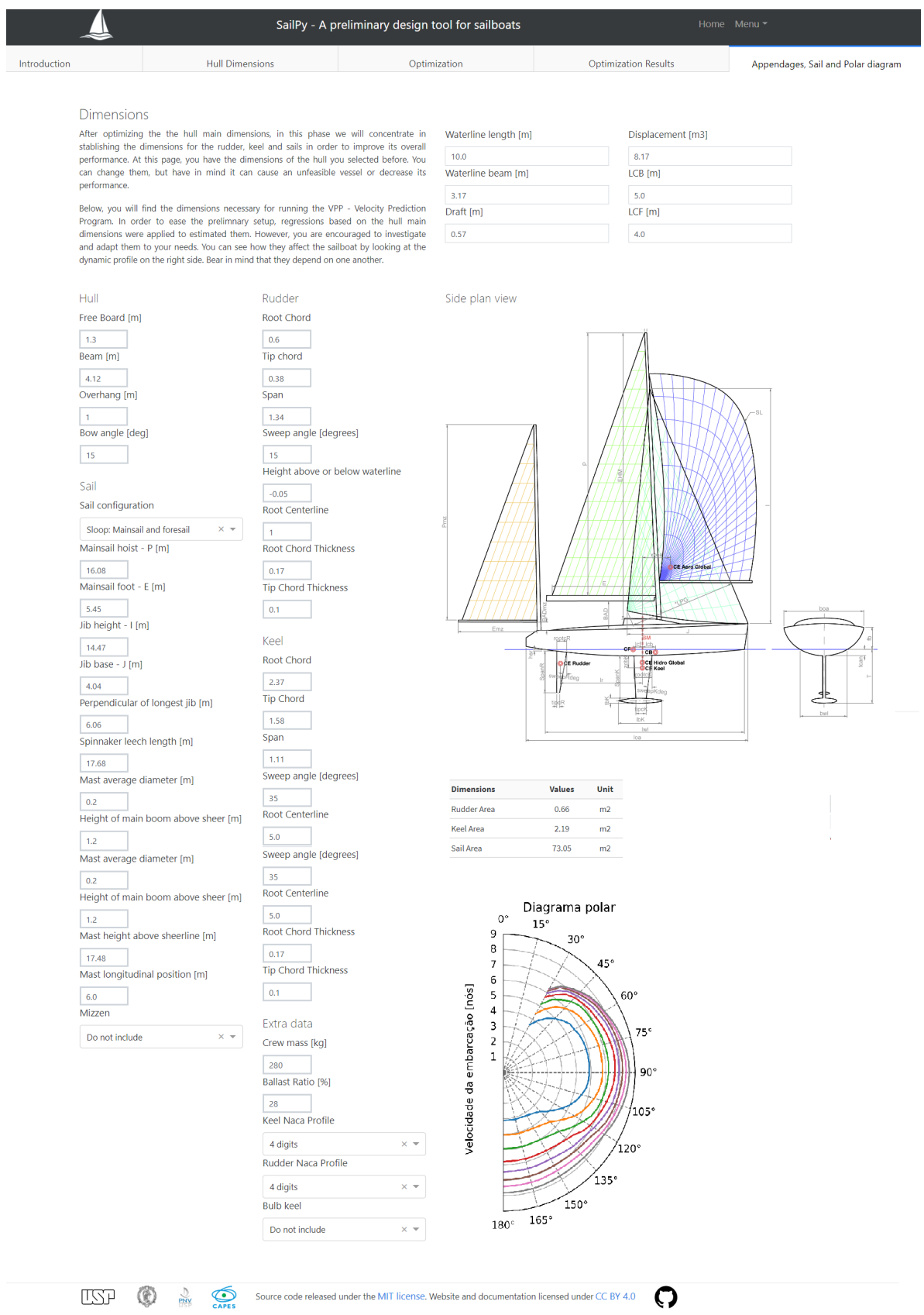




\section{Capítulo 6}

\section{Resultados}

Neste capítulo apresentamos a aplicação da metodologia descrita anteriormente em cinco veleiros que servem de estudo de caso. O capítulo é dividido em duas partes. A primeira parte corresponde ao processo de otimização mono-objetivo, que consiste na otimização unicamente da resistência hidrodinâmica em águas calmas e total (incluindo a resistência adicional). Já a segunda parte, incorpora a otimização a resistência adicional como função objetiva antagônica a resistência em águas calmas.

Para este estudo de caso, a escolha dos veleiros é feita com base nos cascos-mães utilizados para o desenvolvimento da série de Delft. Adicionalmente, o veleiro YD40 utilizado ao longo do livro de Larsson e Eliasson (2001) foi incluído, visto esta ser uma referência no projeto de veleiros e incluir todas as dimensões necessárias para a análise. Estes cinco veleiros têm características distintas, variando entre cascos mais bojudos e mais delgados, desenvolvidos entre 1973 e os anos 2000, e servindo diferentes propósitos (regatas e cruzeiros).

Tabela 5 - Dimensões principais dos veleiros utilizados no estudo de caso

\begin{tabular}{lcccccc}
\hline Dimensões & Unidade & Sysser 1 & Sysser 25 & Sysser 44 & Sysser 60 & YD40 \\
\hline$L_{W L}$ & $m$ & 10 & 10 & 10 & 10 & 10.02 \\
$B_{W L}$ & $m$ & 3.17 & 2.5 & 3.013 & 2.561 & 3.17 \\
$T_{C}$ & $m$ & 0.794 & 0.464 & 0.681 & 0.445 & 0.57 \\
Deslocamento & $m^{3}$ & 9.183 & 4.623 & 8.087 & 4.617 & 7.63 \\
$\mathrm{LCB}^{1}$ & $m$ & -0.229 & -0.199 & -0.329 & -0.455 & -0.35 \\
$\mathrm{LCF}^{1}$ & $m$ & -0.333 & -0.554 & -0.625 & -0.71 & -0.35 \\
$A_{W P}$ & $m^{2}$ & 21.819 & 16.783 & 20.127 & 17.588 & 25.2 \\
$S_{C B}$ & $m^{2}$ & 25.099 & 18.859 & 23.831 & 19.415 & 30.9 \\
$C_{B}$ & & 0.365 & 0.399 & 0.394 & 0.405 & 0.36 \\
$C_{M}$ & & 0.646 & 0.727 & 0.712 & 0.748 & 0.65 \\
$C_{P}$ & & 0.564 & 0.548 & 0.554 & 0.541 & 0.56 \\
$C_{W P}$ & & 0.688 & 0.671 & 0.668 & 0.687 & 0.79 \\
\hline
\end{tabular}

$\overline{1}$ Medidos a partir da seção mestra e positivos à vante 
A variedade em suas características nos permite verificar a versatilidade da metodologia. A Tabela 5 mostra as dimensões principais de cada um dos veleiros. O plano de linhas de cada uma das embarcações é incluso nos Apêndices A.

Nas análises de otimização seguintes convencionou-se analisar o veleiro para faixas de Froude entre 0.2 e 0.5 e valores de adernamento entre 0 e 60 graus.

Como uma ilustração dos diferentes cascos analisados, podemos fazer um comparativo entre cascos de diferentes séries. A série I foi desenvolvida baseada no casco Standfast 43, projetado por Frans Maas em 1973 e tem características de um veleiro cruzeiro-regata. As linhas do casco são apresentadas na Figura 15.

Figura 15 - Casco-mãe série I (Sysser 1)

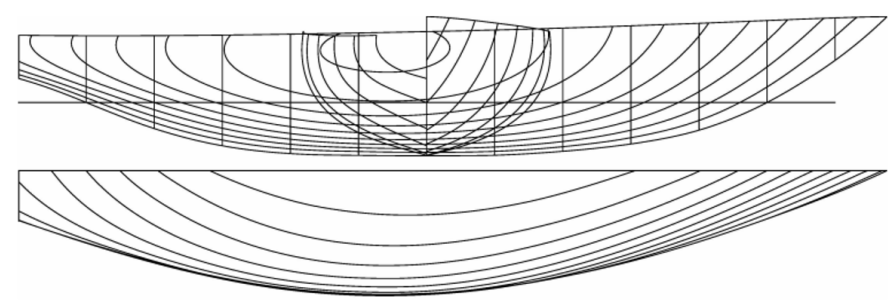

Fonte: Kleijweg (2016)

Em contrapartida, as três séries seguintes foram baseadas em um projeto de Van de Stadt desenvolvido na década de 80, com um casco com peso significativamente menor, levando a um deslocamento e calado menores que o seu antecessor. As linhas do casco são apresentadas na Figura 16.

Figura 16 - Casco-mãe série II, III e VII (Sysser 25)

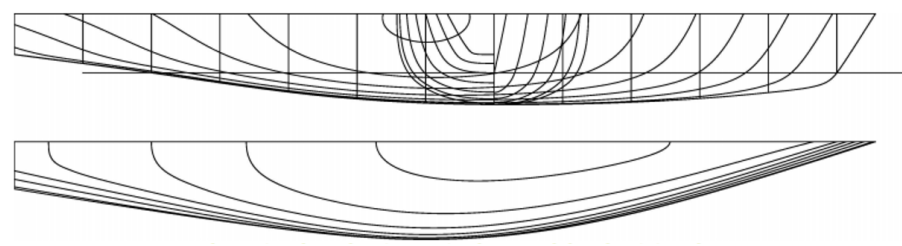

Fonte: Kleijweg (2016)

\subsection{Otimização mono-objetivo}

O processo de otimização é aplicado com o intuito de reduzir a resistência hidrodinâmica para para uma faixa de Froude entre 0.2 e 0.45 . O processo é aplicado individualmente para cada uma destas velocidades utilizando o valor médio do incremento da resistência devido ao adernamento para uma faixa de ângulo entre 0 e 40 graus. 
O modelo aplica as restrições descritas anteriormente e permite que os parâmetros do casco variem em um intervalo de $10 \%$ enquanto o comprimento do casco será mantido fixo. O intuito destes limites é preservar as características principais do casco e avaliar o potencial de melhoria com ajustes mínimos das dimensões.

No que diz respeito a configuração do algoritmo genético, são utilizadas os mesmo valores apresentados na Tabela 4.

\subsubsection{Resistência em águas calmas}

Utilizando apenas a resistência em águas calmas como função objetivo, os cinco cascos estudados têm suas dimensões otimizadas. A análise é realizada individualmente para cada número de Froude. O resultado pode ser observado na Figura 17, onde são comparados os valores de resistência entre o casco original e o casco com menor resistência ao avanço ao final do processo de otimização. Os valores do ganho percentual entre o objetivo inicial e final são mostrados no topo de cada gráfico.

Figura 17 - Otimização para diferentes faixas de Froude e adernamento
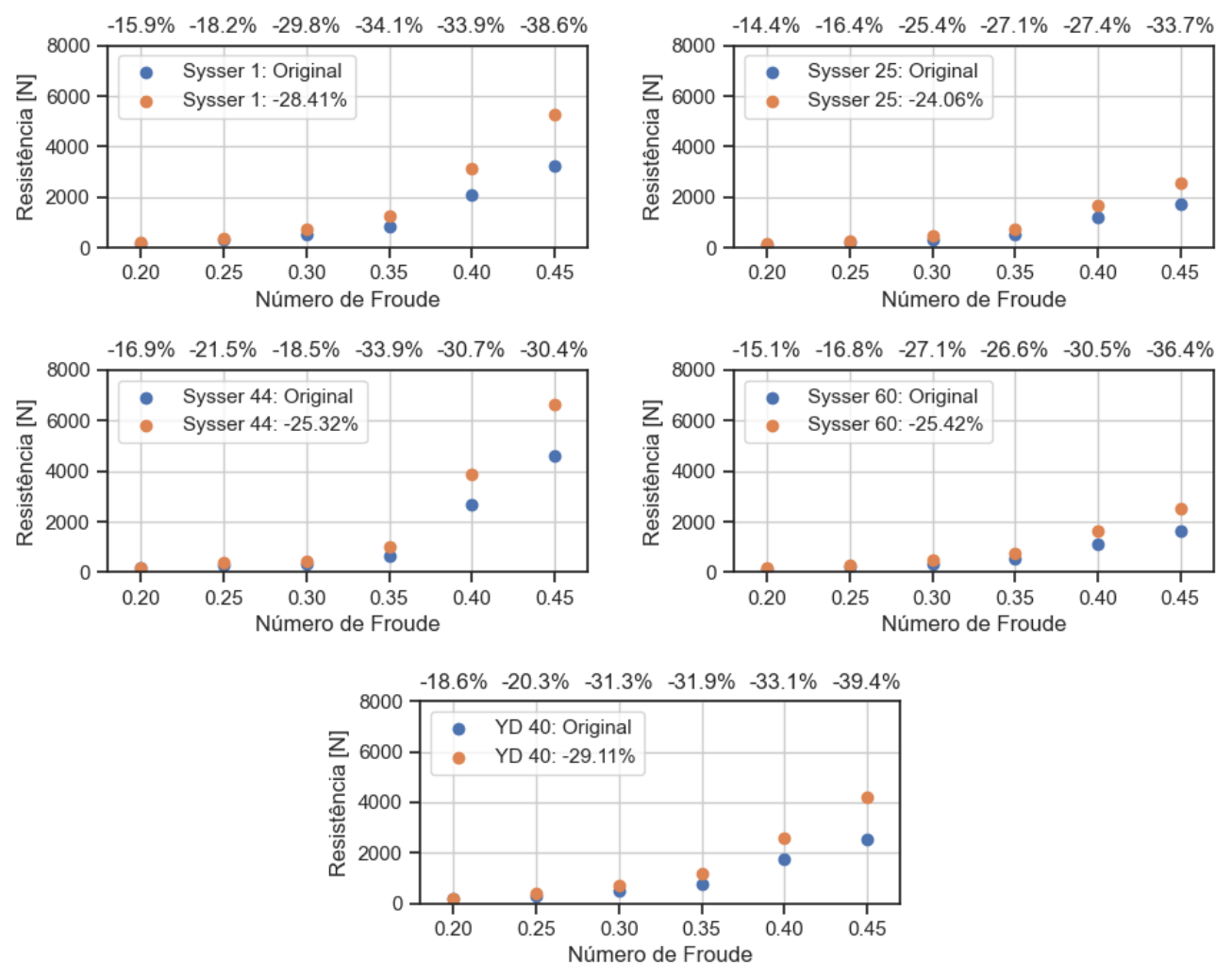

Os resultados indicam que os ganhos são mais significativos para números de Froude maiores, chegando a ganhos de cerca de $40 \%$ para números de Froude de 0.4. A razão para tal fato é evidente. A resistência friccional, predominante para velocidades menores, têm um único elemento passível de ser afetado no processo de otimização (área molhada do casco) e portanto permite ganhos menores através da manipulação das dimensões do casco. 
Em contrapartida, a resistência residual que passa a ser dominante em velocidades maiores é largamente afetada por cinco diferentes parâmetros, permitindo que mais alternativas sejam buscadas.

Também é possível observar que os maiores ganhos aconteceram em cascos mais bojudos e que apresentam maiores valores de deslocamento e boca, como o Sysser 1 e YD 40, reforçando a importância destas duas dimensões no cálculo resistência.

Ao final de cada processo de otimização, também é possível consultar as dimensões do casco com menor valor da função objetivo e avaliar como os cascos variam ao longo do processo. O resultado é mostrado na Figura 18, onde os valores apresentam a diferença percentual entre o início e o fim do processo, no qual 1 indica que não houve mudança e salientado pela linhas vermelhas.

Figura 18 - Variação das dimensões ao final do processo

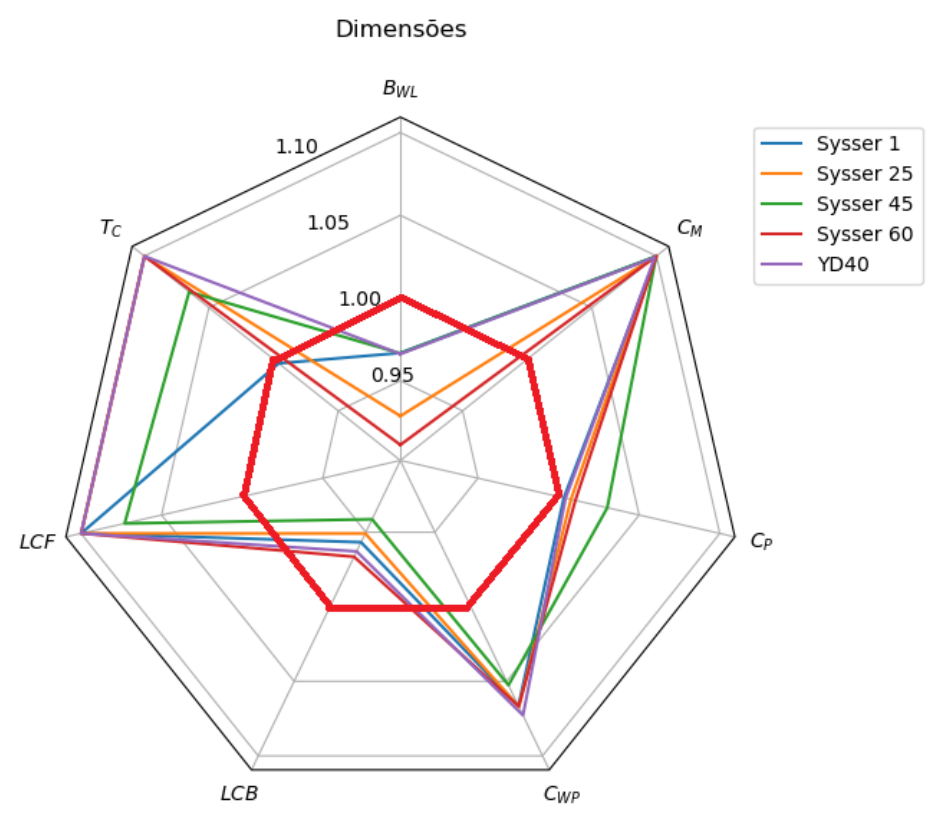

Através da imagem, fica nítido que existe um comportamento semelhante em como as dimensões se alteram ao final do processo de otimização. A tendência, naturalmente, é que os cascos se tornem mais delgados para diminuírem a resistência hidrodinâmica. Este comportamento é refletido na diminuição da boca na linha d'água do casco. Como o deslocamento é mantido fixo neste estudo, este efeito é compensado pelo aumento do calado moldado. De forma semelhante, com o comprimento e deslocamento constantes, e a diminuição da boca, o coeficiente do plano da linha da água aumenta. O fato de que alguns parâmetros atingiram o limite de variação de $10 \%$ indica que expandir o espaço exploratório pode gerar reduções ainda maiores na resistência ao avanço. Contudo, maiores modificações nas dimensões aumentariam consideravelmente os riscos de cascos irreais, o que demandaria uma avaliação individual da viabilidade dos cascos. 


\subsubsection{Resistência total}

Neste segunda parte, analisamos a resistência em águas calmas somada à resistência adicional em ondas. A análise é feita para intervalos de Froude entre 0.2 e 0.45 que corresponde ao valores mínimos e máximos permitidos pela série de Delft para o cálculo da resistência adicional em ondas. Além disto, é necessário admitir uma condição de mar hipotético para mar plenamente desenvolvido. Adota-se para esta análise as seguintes condições:

- Período de onda: 6 segundos;

- Altura significativa de onda: 1 metro;

- Ângulo de incidência: 140 graus;

- Raio de giração: $25 \%$ do comprimento da linha d'água.

Para tais condições de mar, o processo de otimização permite ganhos teóricos entre 24 e $26 \%$. O resultado do método de otimização para os mesmos cinco cascos é apresentado na Figura 19.

Figura 19 - Otimização para diferentes faixas de Froude
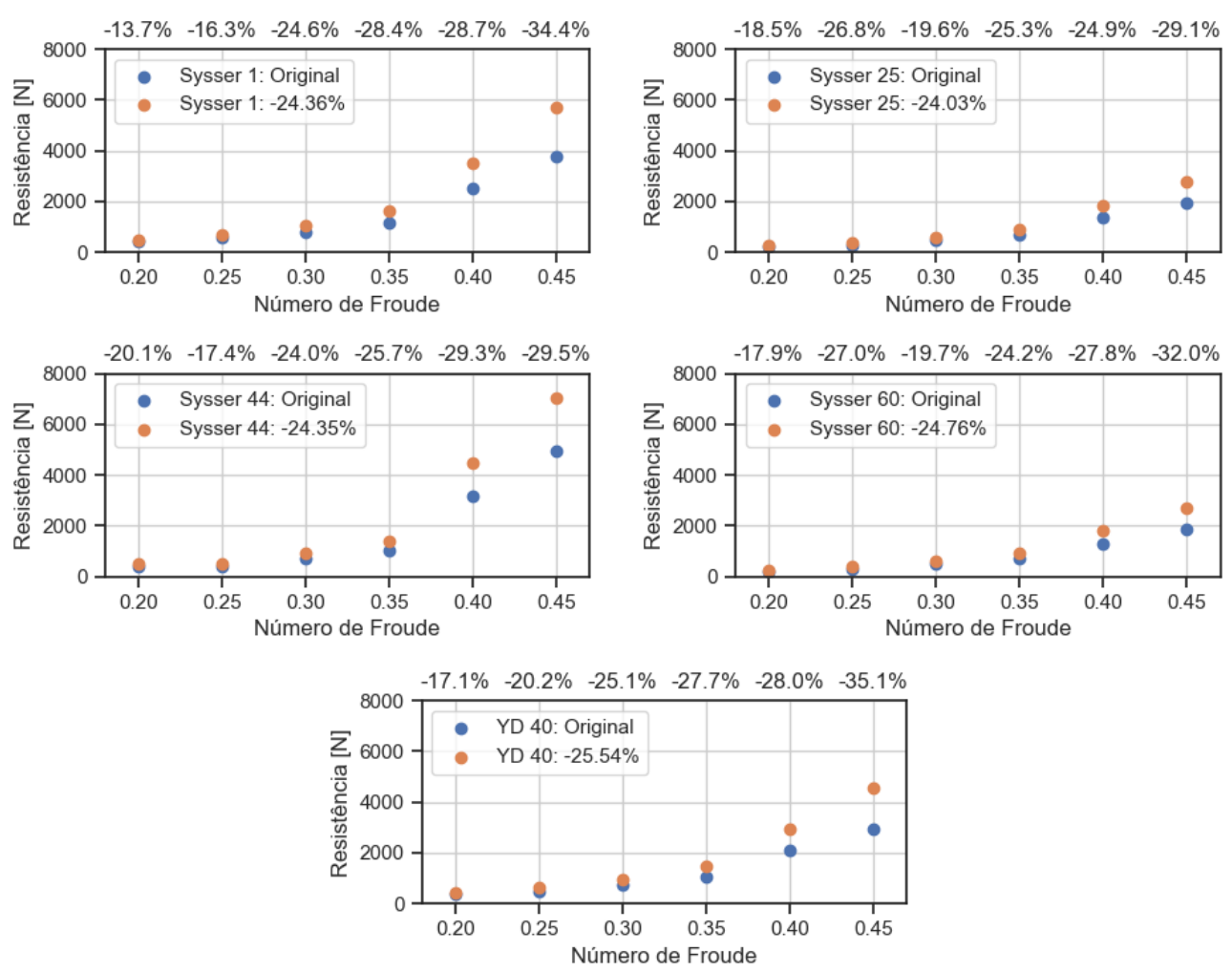

Quando adicionamos a resistência adicional em ondas à análise, nota-se que os ganhos no processo são menores em relação ao processo anterior para o mesmo número de 
gerações. AInda que a resistência adicional corresponda à 10-15\% da resistência total. Tal fato pode ser justificado pelo comportamento antagônico da resistência em águas calmas e adicional em ondas, fazendo com que uma solução ideal seja menos trivial. Diferentemente da resistência em águas calmas, a resistência em onda, por exemplo, se beneficia de cascos com deslocamentos maiores.

As dimensões dos cascos com menor resistência hidrodinâmica total são mostradas na Figura 20. O comportamento das dimensões ao final do processo é muito semelhante a análise anterior. A exceção, no entanto, é o coeficiente prismático que fazendo parte do cálculo da resistência adicional em onda, desta vez apresenta valores menores que o casco original.

Figura 20 - Variação das dimensões ao final do processo

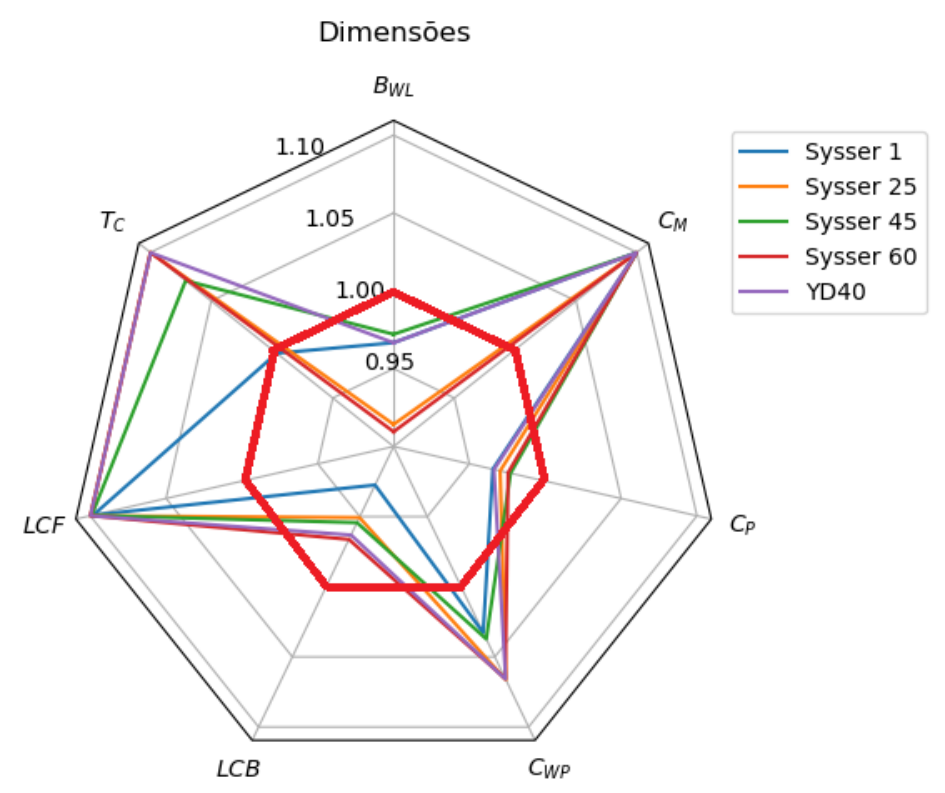

\subsection{Otimização multi-objetivo}

A análise anterior tornou evidente que a adição da resistência adicional em ondas introduz uma relação de compromisso entre adelgar o casco e aumentar o seu deslocamento.

Para aprofundar o entendimento desta relação, esta seção aplica uma análise multi-objetivo que visa minimizar a resistência em águas calmas e a resistência adicional em ondas simultaneamente. As condições de mar são as mesmas adotadas na análise mono-objetivo. O casco analisado é o Sysser 60 operando em um número de Froude de 0.3. O resultado é mostrado na Figura 21, no qual as cores indicam a ordem em que os indivíduos são gerados, sendo o amarelo os últimos gerados ao longo do processo.

Pode-se notar que há a formação da fronteira de Pareto e que os pontos convergem no início do processo em direção a fronteira, como denotado pelo esquema de cores. 
É na fronteira de Pareto que o usuário pode encontrar os cascos que melhor atendem ambos objetivos. Nota-se também que há cascos inválidos gerados durante o processo, especialmente no início do processo. Na fronteira de Pareto, contudo, não existem indivíduos inválidos, indicando que a faixa de variação possa ser pequena para ativar as restrições. Além do mais, ganhos substanciais são obtidos quando comparados com o casco inicial (asterisco vermelho).

Figura 21 - Otimização para resistência em águas calmas e adicional em ondas

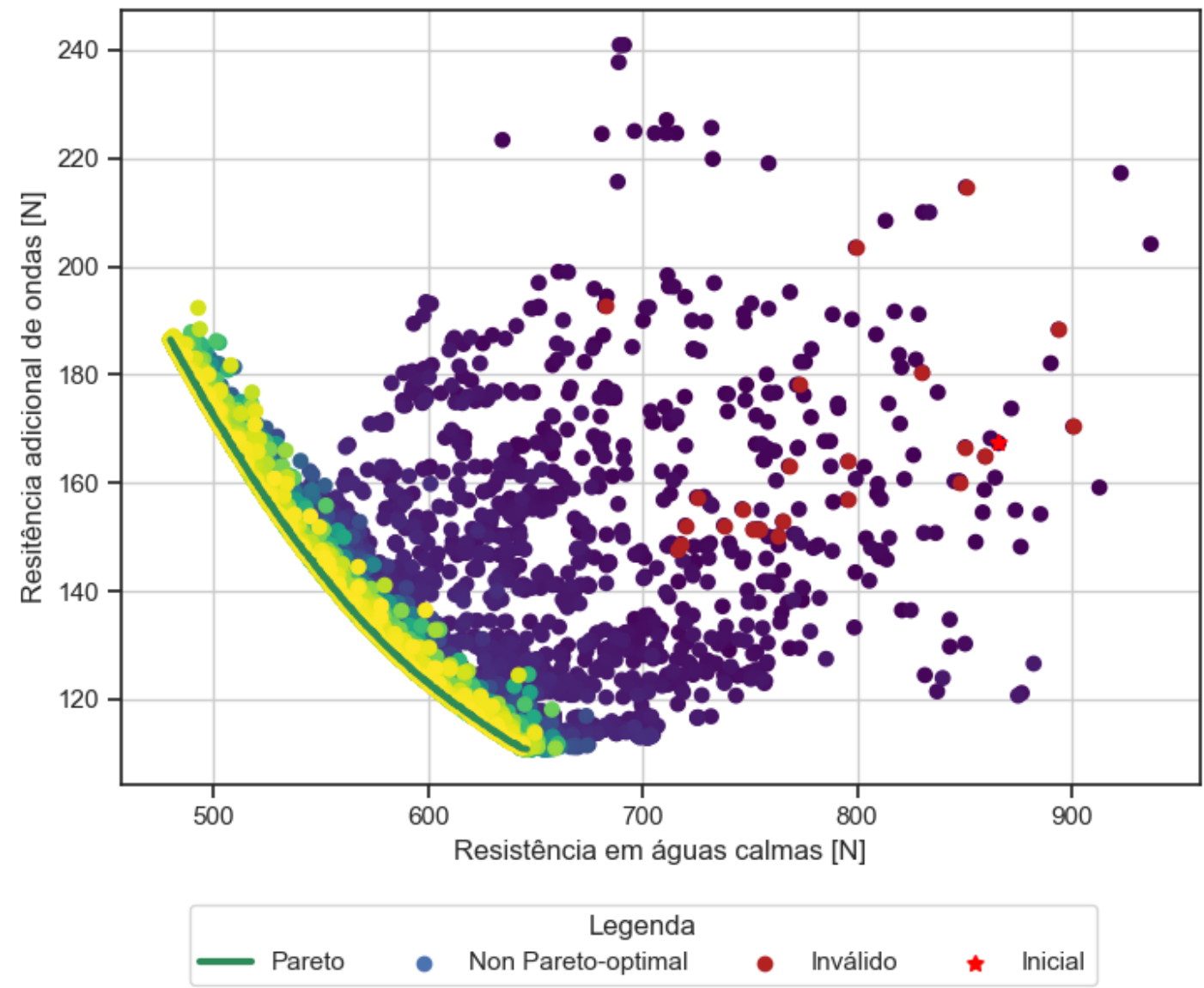

Quando os cascos presentes na fronteira de Pareto são analisados individualmente, nota-se que há uma multiplicidade de soluções para valores similares de resistência, reforçando a hipótese de que o espaco amostral poderia ser expandido. Pode-se avaliar como as dimensões foram alteradas ao longo do processo em termos percentuais através da Figura 22. A cor amarela que denota as últimas gerações durante o processo, indicando que os cascos finais tiveram uma redução na dimensão da boca e, devido ao comprimento e deslocamento se manterem fixos, é possível notar que o calado se comportou de forma oposta, aumentando nos casos em que a boca decrescia. 
Figura 22 - Dimensões variando no processo

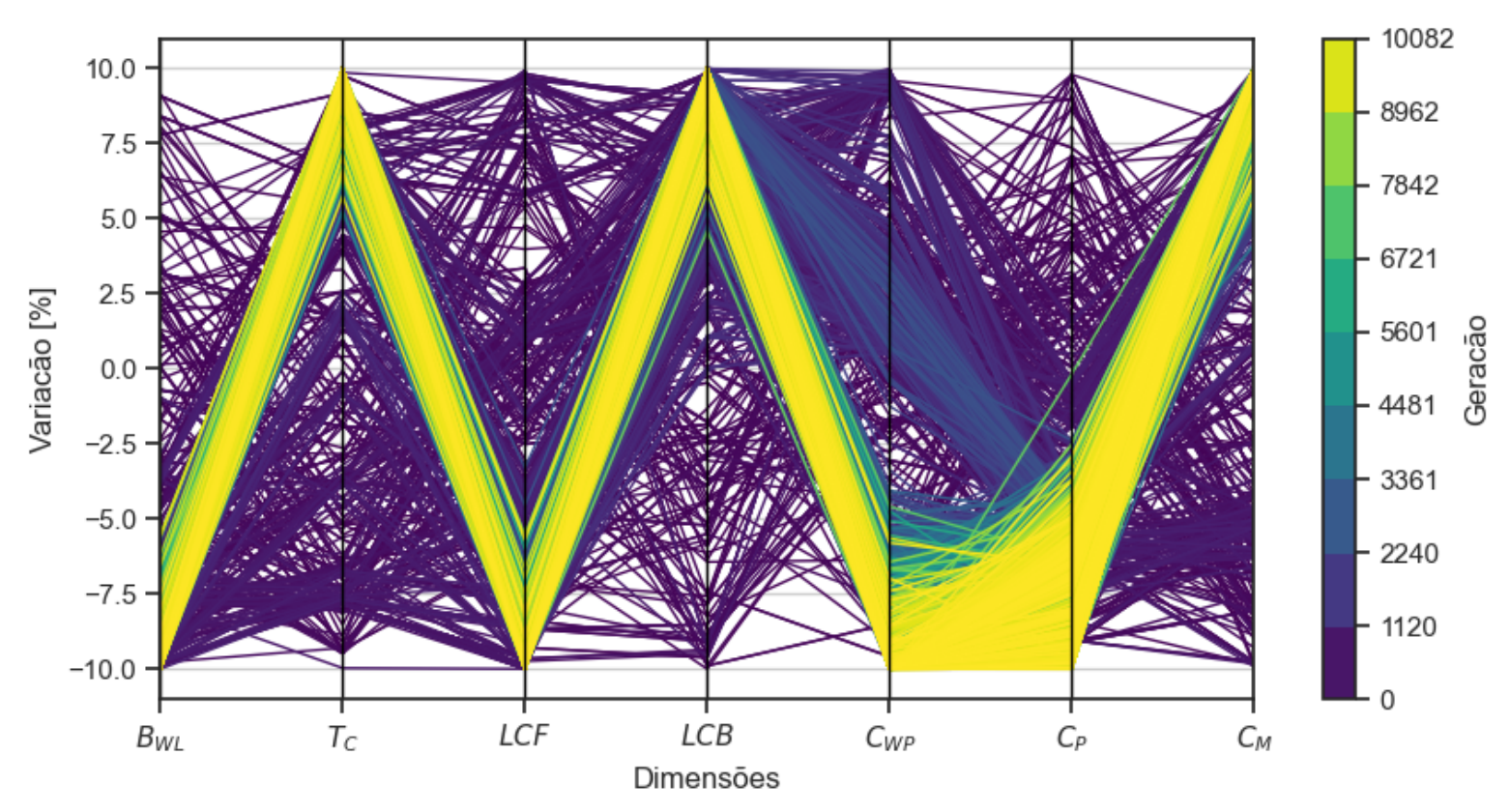




\section{Capítulo 7}

\section{Discussão}

Neste capítulo são abordados aspectos relacionados à análise apresentada no capítulo anterior que não necessariamente fazem parte do processo de otimização ou do estudo de caso apresentado, como a seleção do melhor indivíduo que cabe ao usuário ao fim o processo.

\subsection{Seleção do melhor indivíduo}

Os indivíduos fornecidos pela fronteira de Pareto representam o conjunto de indivíduos ideais. Contudo, este conjunto de soluções pode conter um número de indivíduos que torne inviável a análise, uma a uma, pelo projetista. Em virtude disso, um processo sistemático e dirigido para a escolha do melhor indivíduo deve ser estabelecido.

A seleção do melhor indivíduo acontece quando se estabelece graus de importância para cada um dos objetivos. Atribuindo valores entre 0 e 10 para a importância de cada objetivo, é possível determinar através de uma média ponderada qual o indivíduo mais adequado. Yoon e Hwang (1981) sugere uma escala de 1 a 10, ainda que outras escalas sejam possíveis devido a inerente subjetividade desta avaliação. A escala adaptada pode ser vista na Tabela 6.

Tabela 6 - Escala adotada

\begin{tabular}{lc}
\hline Escala descritiva & Equivalente numérico \\
\hline Extremamente irrelevante & 0 \\
Muito irrelevante & 1 \\
Irrelevante & 3 \\
Indiferente & 5 \\
Importante & 7 \\
Muito importante & 9 \\
Extremamente importante & 10 \\
\hline
\end{tabular}

Fonte: Yoon e Hwang (1981) 
A representação matemática desse processo é dado na Equação (7.1), onde $\omega_{k}$ representa o peso do atributo segunda a escala já apresentada (valores positivos para maximizar e negativos para minimizar), e $f_{k}(X)$ o valor do objetivo em módulo.

$$
F_{P}(X)=\sum_{i=1}^{m}\left(\omega_{k} \cdot f_{k}(X)\right)=\omega_{1} \cdot f_{1}(X)+\omega_{2} \cdot f_{2}(X)+\ldots+\omega_{m} \cdot f_{m}(X)
$$

Vale ressaltar que os valores dos objetivos são normalizados entre si para evitar que objetivos com magnitude maiores tenham uma influência maior do que aqueles com magnitude inferiores.

Está função está implementada na ferramenta, permitindo que o usuário atribua diferentes pesos à função objetivo. A atribuição de pesos, de forma empírica, permite que seja possível selecionar o indivíduo gerado, dentro da fronteira de Pareto, que melhor atenda a estes requisitos. Dessa forma, o usuário pode ter um direcionamento inicial de qual região da fronteira de Pareto podem estar os cascos que melhor satisfazem suas necessidades.

\subsection{Sensibilidade aos parâmetros}

A análise de sensibilidade pode ser definida como o estudo da variação dos resultados de um modelo (numérico ou não)em função das entradas fornecidas e como estas podem ser endereçadas a diferentes fontes de incerteza (SALTELLI et al., 2000). Analogamente, podemos mensurar como cada uma das dimensões é capaz de influenciar os objetivos quando sua magnitude é alterada e entender quais dimensões podem levar a melhorias mais significativas durante o processo de otimização.

A Figura 23 mostra a variação média para os cinco cascos analisados ao longo do capítulo anterior. Nela, pode-ser notar que os parâmetros afetam os objetivos de forma variada. Larsson e Eliasson (2001) já destacava a influência que o deslocamento pode ter no cálculo da resistência, o que fica explícito pelos altos valores para a curva de $C_{B}$ mostrados na Figura 23. O autor também já apontava que alterações na boca e no calado a fim de tornar o casco mais delgado teriam menores efeitos do que alterações no deslocamento.

Com base nos gráficos, nota-se as relações de compromisso inerentes ao projetos e também indica possíveis soluções para resolver estes compromissos. Por exemplo, ao aumentar o deslocamento da embarcação, o projetista pode fazer ajustes em coeficientes de forma como o centro longitudinal de flutuação (LCF) afim de contrapor o ganha em resistência. 
Figura 23 - Sensibilidade média para resistência em águas calmas
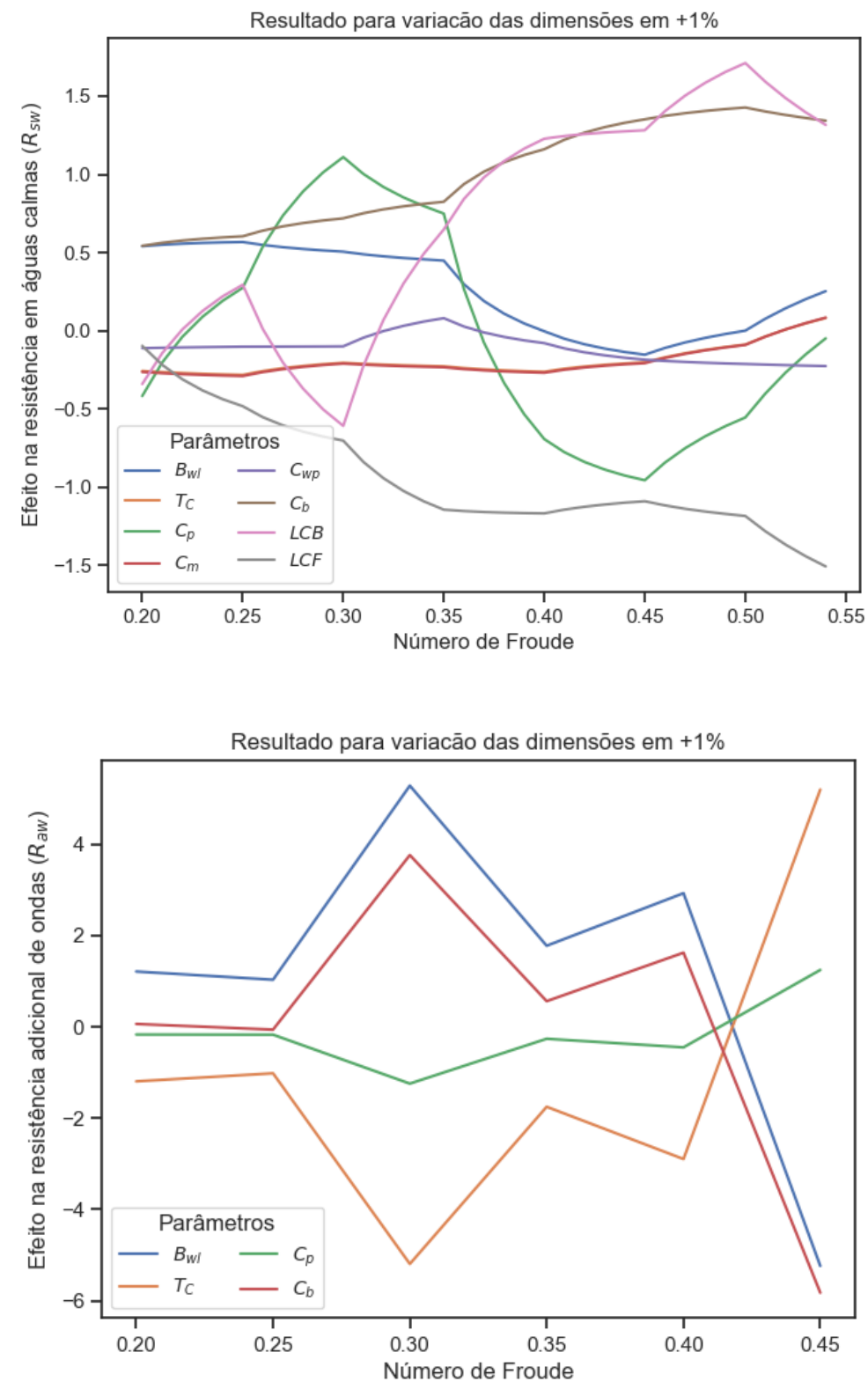

\subsection{Análise do coeficiente prismático e LCB}

Em seu livro, Larsson e Eliasson (2001) utiliza a série Delft para explorar quais os valores ideias do coeficiente prismático $\left(C_{P}\right)$ e do centro longitudinal de carena (LCB) para um certo conjunto de dimensões já estabelecidos. Para tanto, o autor representa através de um gráfico os valores obtidos de resistência residual em função destes coeficientes, usando a Equação 3.4 .

Para validarmos a metodologia aplicada neste trabalho, propõe-se utilizar o método aplicado ao longo trabalho utilizando as mesmas dimensões básicas do casco. Em princípio, espera-se obter os mesmo valores de $C_{P}$ e $L C B$ através do método de otimização. 
Na Figura 24 mostramos as curvas desenvolvidas por Larsson e Eliasson (2001) e os valores obtidos através deste método. O método desenvolvido pelo autor considera os dois parâmetros isoladamente desconsiderando o efeito entre si.

Figura 24 - Relação entre parâmetros e resistência residual

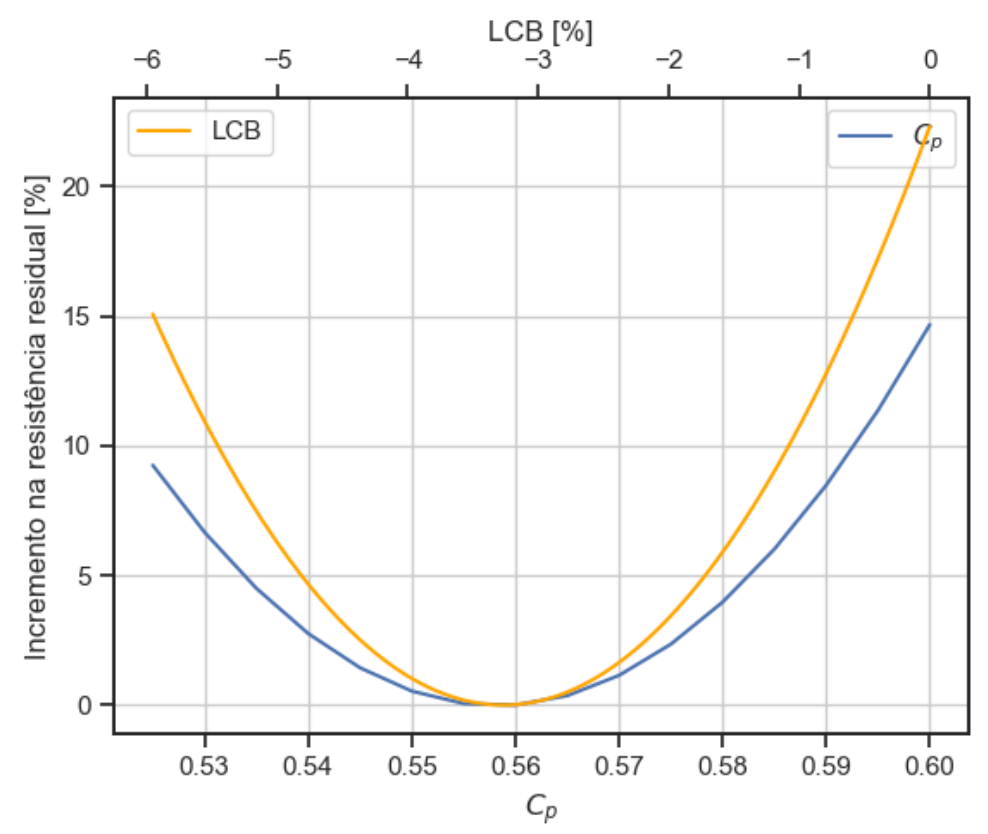

Aplicando a metodologia desenvolvida neste trabalho, mantendo todos os valores dimensionais fixos com exceção de $C_{P}$ e $L C B$, obtemos os valores de $C_{P}=0.553$ e $L C B=-3.266 \%$, similares aos valores obtidos por Larsson e Eliasson (2001) e mostrados na Figura 24.

Portanto, os mesmo valores são obtidos de forma automatizada, sem necessitar de um processo racional por parte do projetista envolvendo a representação e análise de parâmetros dimensionais. Não apenas isso, como também considerar parâmetros simultaneamente possibilita capturar efeitos combinados e cumulativos. 


\section{Capítulo 8}

\section{Conclusões}

Através deste trabalho desenvolveu-se uma ferramenta para análises de redução da resistência ao avanço de casco aplicados ao projeto conceitual de veleiros. O principal intuito do trabalho foi estabelecer a base de uma ferramenta que possa ser aprimorada no futuro através de um esforço coletivo de seus usuários.

Os resultados preliminares de sua aplicação, apresentado em estudos de caso no capítulo anterior, mostram a possibilidade de ganhos na redução da resistência hidrodinâmico do casco de veleiros. Estes ganhos podem alcançar 35\% para números de Froude maiores que 0.3 e $20 \%$ para valores menores. Contudo, este tipo de ferramenta não tenciona substituir o conhecimento empírico e qualitativo do usuário, mas indicar possíveis aspectos de melhoria orientado ao desempenho final. Tampouco a ferramenta permite concluir que as mudanças serão de fato benéficas quando todas as demais características do casco, e.g. estabilidade, manobrabilidade, forem consideradas.

Em tempo, vale ressaltar que não há um casco ideal para todas as condições de operação. Haverá sempre relações de compromisso que o usuário deverá avaliar tendo em mente a aplicação que se destina ao veleiro.

A metodologia aqui apresentada, no entanto, acabou por não ser inteiramente validada ao longo deste trabalho. Sugere-se que as dimensões obtidas através do processo de otimização sejam aplicadas efetivamente na geração de um casco afim de verificar a suavidade da superfície do casco gerado. Complementarmente, análises mais precisas de resistência podem ajudar a verificar se os valores obtidos, especial na resistência adicional em ondas, são razoáveis.

Em trabalhos futuros, acredita-se que este estudo possa servir de base, juntamente com a ferramenta desenvolvida, para análises mais robustas aplicando métodos mais robustos na análise hidrodinâmica do casco, como teoria das faixas ou análises em CFD. Análises como estas também permitiriam avaliar características mais específicas, tais como percepção de conforto pelo velejador e sua tripulação, aceleração vertical da embarcação 
em condições mais severas de operação e navegabilidade, além de permitir que a curvatura do casco também seja analisada.

Outra campo de estudo possível é a inclusão do efeito de apêndices, mastreação e velame na análise através de um VPP. Ainda que o desenvolvimento deste escopo mais abrangente seja facilitado por trabalhos como Gerritsma e Keuning (1992) e Keuning e Sonnenberg (1998) que detalham as forças envolvidas no projeto, aplicar um processo de otimização pode mostrar-se custoso computacionalmente e o número de variáveis envolvidas dificultar a convergência para um mínimo global.

Através da ferramenta disponibilizada em código aberto, espera-se que estas e outras melhorias sejam agregadas no futuro por entusiastas, projetistas e acadêmicos. 


\section{Referências}

BARBARINI, L. H. M. Síntese de cascos de embarcações através de métodos de otimização aplicados a curvas B-Spline. Tese (Doutorado) — Universidade de São Paulo, 2007. Citado na página 26.

BREWER, E. S. Ted Brewer Explains Sailboat Design. [S.1.]: International Marine Publishing Company, 1985. Citado na página 46.

DEAKIN, B. Methods of assessing the safety of cruising yachts in terms of their stability". In: RINA. The Seaworthy Cruising Yacht Conference. [S.l.], 1991. Citado na página 45.

DEB, K. et al. A fast elitist non-dominated sorting genetic algorithm for multi-objective optimization: Nsga-ii. In: SPRINGER. International Conference on Parallel Problem Solving From Nature. [S.1.], 2000. p. 849-858. Citado na página 27.

DEBORD, F. J. et al. Design optimization for the international americas cup class. In: Transactions of the 2002 SNAME Annual Meeting. [S.l.: s.n.], 2002. Citado na página 22.

FASSARDI, C.; HOCHKIRCH, K. Sailboat design by response surface optimization. In: High Performance yacht Design Conference, Auckland, New Zealand. [S.l.: s.n.], 2006. Citado 3 vezes nas páginas 21, 22 e 26.

FORTIN, F.-A. et al. DEAP: Evolutionary algorithms made easy. Journal of Machine Learning Research, v. 13, p. 2171-2175, jul 2012. Citado na página 51.

FOSSATI, F. Aero-hydrodynamics and the performance of sailing yachts: the science behind sailing yachts and their design. [S.1.]: A\&C Black, 2009. Citado 4 vezes nas páginas 22, 25, 29 e 33.

GERRITSMA, J.; KEUNING, J. Sailing yacht performance in calm water and in waves. In: 12th International Symposium on Yacht Design and Construction, HISWA. [S.l.: s.n.], 1992. Citado 2 vezes nas páginas 30 e 68.

GIL, A. C. Como elaborar projetos de pesquisa. São Paulo, v. 5, n. 61, p. 16-17, 2002. Citado na página 41.

HADKA, D.; REED, P. Borg: An auto-adaptive many-objective evolutionary computing framework. Evolutionary computation, MIT Press, v. 21, n. 2, p. 231-259, 2013. Citado na página 39.

KANTOROWITZ, D. Aprimoramento de programa de predicão de velocidades de um veleiro monocasco. [S.1.]: Trabalho de conclusão de curso - USP, 2019. Citado na página 53. 
KEUNING, J.; KATGERT, M. A bare hull resistance prediction method derived from the results of the delft systematic yacht hull series extended to higher speeds. In: International Conference on Innovation in High Performance Sailing Yachts, Lorient, France. [S.l.: s.n.], 2008. Citado 2 vezes nas páginas 25 e 31.

KEUNING, J.; KATGERT, M. The influence of heel on the bare hull resistance of a sailing yacht". In: The 2nd International Conference on Innovation in High Performance Sailing Yachts, Lorient, France. [S.l.: s.n.], 2010. Citado na página 32.

KEUNING, J.; VERMEULEN, K.; HAVE, H. ten. An approximation method for the added resistance in waves of a sailing yacht. In: 2 nd International Symposium on Design and Production of Motor and Sailing Yachts MDY '06, Madrid, Spain. [S.l.: s.n.], 2006. Citado 3 vezes nas páginas 25, 32 e 34 .

KEUNING, J. A.; SONNENBERG, U. B. Approximation of the Hydrodynamic Fforces on a Sailing Yacht Based on the Delft Systematic Yacht Hull Series. [S.1.]: Delft University of Technology, Faculty of Mechanical Engineering and Marine Technology, Ship Hydromechanics Laboratory, 1998. Citado 5 vezes nas páginas 25, 31, 34, 44 e 68.

KLEIJWEG, N. A bare hull upright trimmed resistance prediction for high performance sailing yachts. 2016. Citado 2 vezes nas páginas 25 e 56.

LARSSON, L.; ELIASSON, R. E. Principles of yacht design. Marine Technology and SNAME News, Society of Naval Architects \& Marine Engineers, v. 38, n. 4, p. 11, 2001. Citado 11 vezes nas páginas 22, 26, 29, 32, 34, 35, 55, 64, 65, 66 e 76.

MARCHAJ, C. A. Sailing Theory and Practice. [S.l.]: Dodd, Mead \& Company, 1964. Citado na página 46.

NELSON, R. M.; KIERCZAK, M.; CARLBORG, Ö. Higher order interactions: detection of epistasis using machine learning and evolutionary computation. In: Genome-Wide Association Studies and Genomic Prediction. [S.1.]: Springer, 2013. p. 499-518. Citado na página 38.

OTTOSSON, P.; BROWN, M.; LARSSON, L. The effect of pitch radius of gyration on sailing yacht performance. In: Proceedings of the First High Performance Yacht Design Conf. Auckland, New Zealand. [S.l.: s.n.], 2002. p. 245-254. Citado na página 26.

PARETO, V. Cours d'économie politique. [S.l.]: Librairie Droz, 1964. v. 1. Citado na página 40.

ROUSMANIERE, J. Desirable and undesirable characteristics of offshore yachts. [S.l.]: WW Norton \& Company, 1987. Citado na página 45.

SALTELLI, A. et al. Sensitivity analysis. [S.1.]: Wiley New York, 2000. v. 1. Citado na página 64.

SIMOS, A. N.; ILlUMinATI, C.; PRADO, V. G. do. Programa de prediçãoo de velocidades e simulador dinâmico de veleiros. 21 Congresso Nacional de Transporte Aquaviário, Construção Naval e Offshore, 2007. Citado na página 53.

SPALATELU-LAZAR, M.; LÉNÉ, F.; TURBÉ, N. Modelling and optimization of sails. Computers $\&$ structures, Elsevier, v. 86, n. 13-14, p. 1486-1493, 2008. Citado na página 21. 
TICONA, W. G. C. Algoritmos Evolutivos Multiobjetivo para a Reconstrução de Árvores Filogenéticas. Tese (Doutorado) — Universidade de São Paulo, 2003. Citado na página 40 .

YOON, K. P.; HWANG, C.-L. Multiple attribute decision making methods and applications: A state-of-the-art survey. Berlin: Springer-Verlag, 1981. Citado na página 63. 

Apêndices 



\section{APÊNDICE A - Planos de linhas dos cascos analisados}

Figura 25 - Casco-mãe Série I (Sysser 1)

Standfast 43 - Projetado por Frans Maas em 1973

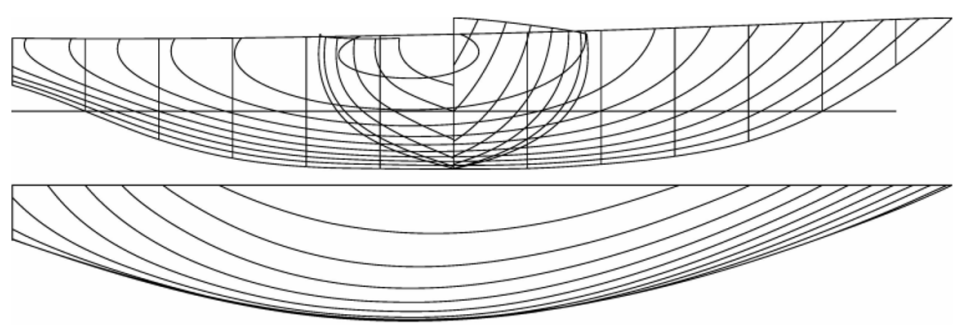

Figura 26 - Casco-mãe Séries II, III, VII (Sysser 25)

Projetado por Van de Stadt na década de 80
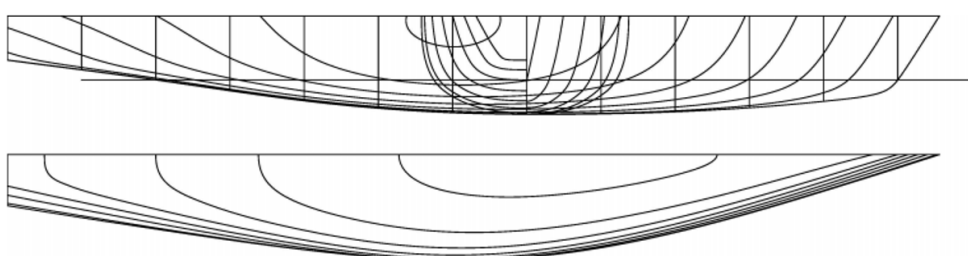

Figura 27 - Casco-mãe Série IV (Sysser 44)

Projetado por Sparkman and Stephens
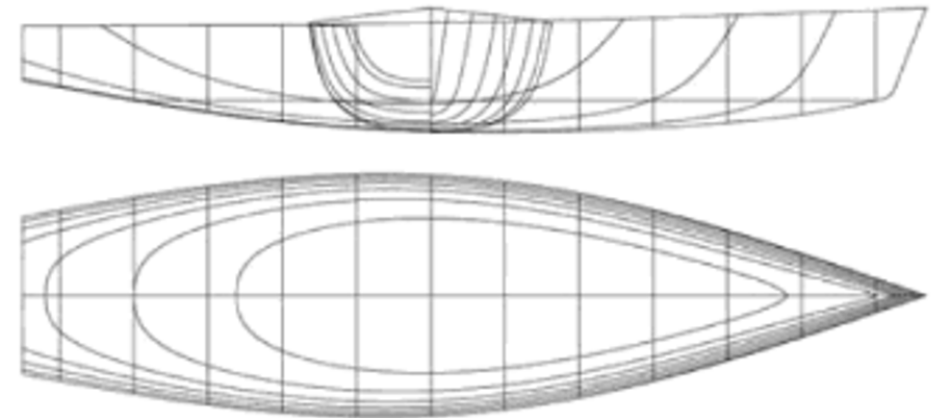
Figura 28 - Casco-mãe Série VI (Sysser 60)
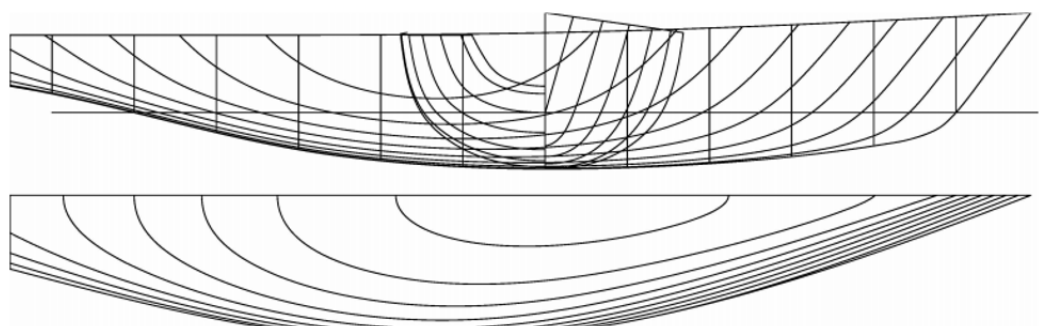

Figura 29 - YD-40

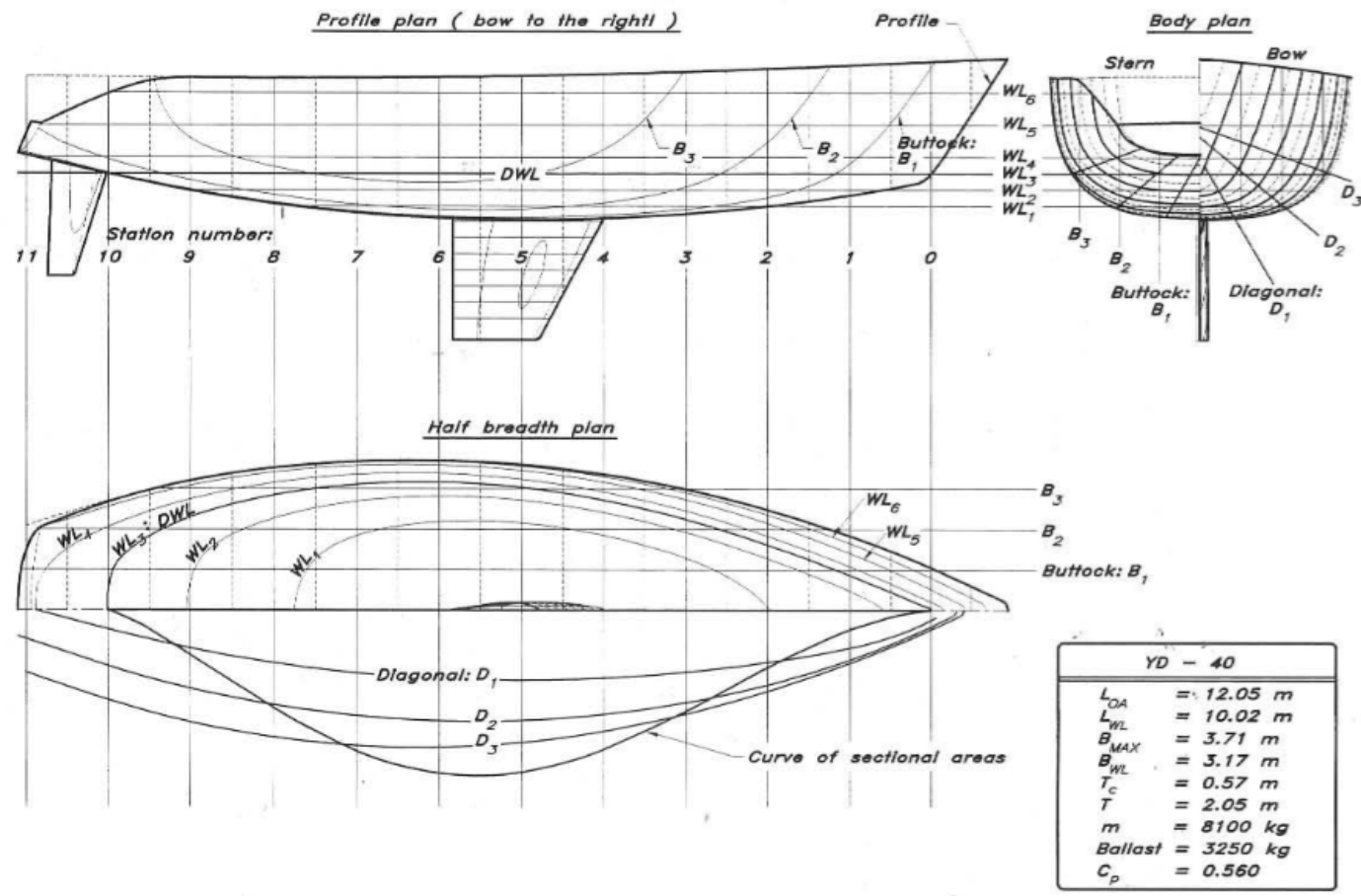

Fonte: Larsson e Eliasson (2001) 